\title{
Theory of $\mathrm{Al} 2 \mathrm{O} 3$ incorporation in $\mathrm{SiO} 2$
}

\author{
Lægsgaard, Jesper
}

\section{Published in:}

Physical Review B Condensed Matter

Link to article, DOI:

10.1103/PhysRevB.65.174104

Publication date:

2002

\section{Document Version}

Publisher's PDF, also known as Version of record

Link back to DTU Orbit

\section{Citation (APA):}

Lægsgaard, J. (2002). Theory of Al2O3 incorporation in SiO2. Physical Review B Condensed Matter, 65(17), 174104. https://doi.org/10.1103/PhysRevB.65.174104

\section{General rights}

Copyright and moral rights for the publications made accessible in the public portal are retained by the authors and/or other copyright owners and it is a condition of accessing publications that users recognise and abide by the legal requirements associated with these rights.

- Users may download and print one copy of any publication from the public portal for the purpose of private study or research.

- You may not further distribute the material or use it for any profit-making activity or commercial gain

- You may freely distribute the URL identifying the publication in the public portal

If you believe that this document breaches copyright please contact us providing details, and we will remove access to the work immediately and investigate your claim 


\title{
Theory of $\mathrm{Al}_{2} \mathrm{O}_{3}$ incorporation in $\mathrm{SiO}_{2}$
}

\author{
J. Lægsgaard \\ Research Center COM, Technical University of Denmark, Bldg. 345v, DK-2800 Lyngby, Denmark
}

(Received 12 November 2001; published 19 April 2002)

\begin{abstract}
Different possible forms of $\mathrm{Al}_{2} \mathrm{O}_{3}$ units in a $\mathrm{SiO}_{2}$ network are studied theoretically within the framework of density-functional theory. Total-energy differences between the various configurations are obtained, and simple thermodynamical arguments are used to provide an estimate of their relative importance at different Al concentrations. Some experimentally accessible quantities (hyperfine parameters, electric-field gradient tensors, and core-level chemical shifts) are derived, and compared with experimental data where available. The results show that $\mathrm{Al}$ ions at low $\mathrm{Al}_{2} \mathrm{O}_{3}$ concentrations will be present as isolated impurities bound to three or four $\mathrm{O}$ atoms, whereas at higher concentrations clusters consisting of four $\mathrm{Al}$ ions will form. In these clusters both four- and five-coordinated $\mathrm{Al}$ can occur, but no energetic preference for the five-coordinated state is found.

DOI: 10.1103/PhysRevB.65.174104

PACS number(s): 61.72.-y, 71.55.-i, 76.30.-v, 78.60.-b
\end{abstract}

\section{INTRODUCTION}

The properties of $\mathrm{Al}$ impurities in silica glass have in recent years become an important topic due to the commercial use of rare-earth doped silica glass for creating active (i.e., light-amplifying) devices used for optical communications systems. Al codoping plays a crucial role in the fabrication of components with useful gain coefficients as it has been found to prevent the clustering of rare-earth dopants which would otherwise strongly reduce the attainable population inversion for high rare-earth concentrations. ${ }^{1,2}$ No microscopic model for the interactions between rare earths and $\mathrm{Al}$ exist at the moment, and even the behavior of $\mathrm{Al}$ impurities in the absence of rare-earth elements is poorly understood. Previous experimental work on crystalline quartz as well as various forms of silicate glasses has indicated that $\mathrm{Al}$ is present in a number of different states depending on the concentration of $\mathrm{Al}$ and other impurities in the material. Extensive electron paramagnetic resonance (EPR) studies have established that $\mathrm{Al}$ in natural quartz is predominantly incorporated in Si-substitutional positions with the missing electron provided by a nearby alkali element (such as $\mathrm{H}, \mathrm{Li}, \mathrm{Na}$, etc.). ${ }^{3-7}$ Also $\mathrm{Al}$ ions implanted in silica were found to occupy substitutional positions, pushing $\mathrm{Si}$ atoms into the interstitial region. ${ }^{8-11}$ However, the state of fully oxidized $\mathrm{Al}$ impurities (that is, $\mathrm{Al}_{2} \mathrm{O}_{3}$ units) in a silica network free of other impurities is still an open question. Brower ${ }^{12,13}$ found EPR evidence of three-coordinated $\mathrm{Al}$ ions in silica fused from natural quartz with low alkali content, but a recent EXAFS ${ }^{14}$ study of glass with an $\mathrm{Al}_{2} \mathrm{O}_{3}$ concentration of $\sim 0.4$ mole $\%$ (compared to the $\sim 10-100 \mathrm{ppm}$ weight $\mathrm{Al}$ concentration in natural quartz) found only evidence of fourcoordinated $\mathrm{Al}$ species. NMR studies at still higher $(>1$ mole \%) concentrations resolve signals from both four-, five-, and six-coordinated $\mathrm{Al}$ (the assignment of the five-coordinated signal is somewhat controversial). ${ }^{15-19}$

A number of theoretical investigations of $\mathrm{Al}$ impurities in silica have appeared over the years, most of them being concerned with the structure and hyperfine parameters of $\mathrm{Si}$ substitutional $\mathrm{Al}$ with or without compensating ions. ${ }^{20-26}$ Such calculations have played an important role in establishing the structural models for compensated substitutional $\mathrm{Al}$ impurities. In addition, small molecules and zeolite structures containing oxidized $\mathrm{Si}$ and $\mathrm{Al}$ ions have been studied, primarily with the purpose of extracting electric-field gradients (EFG's) at $\mathrm{Si}, \mathrm{Al}$, and $\mathrm{O}$ nuclei. ${ }^{27,28}$

The purpose of the present work is to shed light on the behavior of $\mathrm{Al}$ in lightly doped $\left(\leqslant 1\right.$ mole \% $\left.\mathrm{Al}_{2} \mathrm{O}_{3}\right) \mathrm{SiO}_{2}$ by means of parameter-free density-functional theory (DFT). To this end, some simple structural models for $\mathrm{Al}_{2} \mathrm{O}_{3}$ units in a $\mathrm{SiO}_{2}$ matrix are investigated. The quantities of interest are total energies and geometric structures, hyperfine coupling constants, core-level shifts, and electric-field gradients. Simple thermodynamic models based on the total-energy results serve to give a feel for the magnitude of entropy effects. The calculations are done in repeated-cell geometries based on crystalline quartz forms. The possibility of generalizing the results to the important case of amorphous silica is carefully discussed, although no attempt at a direct simulation of the amorphous environment is made. On the basis of the theoretical findings various experimental results are analyzed and discussed.

The rest of the paper is organized as follows: In Sec. II the theoretical approach is outlined. This includes both the structural models considered, and the calculational techniques employed. In Sec. III the results of the DFT calculations and some thermodynamical model calculations are presented. In Sec. IV these results together with experimental information are used as a basis for discussing various models for the behavior of $\mathrm{Al}$ impurities in silica glass. Section V summarizes the results and conclusions.

\section{THEORETICAL APPROACH}

\section{A. Structural models for $\mathrm{Al}_{2} \mathrm{O}_{3}$ in silica}

The investigation of impurity behavior in silica materials is greatly complicated by the fact that even the energy landscape for pure silica has a multitude of local minima. This is evidenced by the existence of 19 crystalline silica allotropes and also by the ease with which amorphous silica is formed. Further complications are, of course, introduced by the addition of other chemical species than the network constituents, and an exhaustive exploration of the local energy minima exhibited by a reasonably sized piece of impurity-containing 
silica using accurate quantum-mechanical methods at the moment appears computationally prohibitive.

The complexity of the energy landscape may be greatly reduced by assuming a crystalline host material and neglecting the possibility of network topology reconstructions around the impurities. This approach is supported by the observation that the local chemical environment around a particular atom (which experimentally can be probed through neutron scattering or x-ray diffraction) in amorphous silica is similar to that in the crystalline forms. The disorder comes about through a loss of intermediate- and long-range order. Therefore local impurity chemistry should not differ too much between crystalline and amorphous silica, and the use of crystalline impurity hosts in theoretical studies has considerable merit in predicting local observables such as hyperfine parameters and core-level shifts even for the amorphous case. This strategy is also adopted in the present work, using in most cases crystalline $\alpha$-quartz as the host material. However, it is important to keep in mind that the results obtained are, in principle, specific for the chosen crystal form, and that their validity further depends on the assumption that no reconstructions of the network topology takes place.

Due to the high degree of local chemical order in silica, the nearest-neighbor shell of a given atom can be unambigously identified, even in the impurity geometries to be considered in this paper. Therefore the concept of coordination number (or number of atoms in the nearest-neighbor shell) of a given atom is well defined. In the following, $X[n]$ will denote an atom of type $X$ with $n$ nearest neighbors. For instance, $\mathrm{Al}[4]$ denotes an $\mathrm{Al}$ atom bonded to four $\mathrm{O}$ atoms, whereas $\mathrm{O}[2]$ denotes an $\mathrm{O}$ atom bonded to two $\mathrm{Si} / \mathrm{Al}$ atoms.

Even with the above-mentioned restrictions a number of $\mathrm{Al}$ impurity states can be imagined, depending on the number of $\mathrm{Al}$ atoms present. In the following only the simplest and most obvious configurations will be considered. Introduction of an $\mathrm{Al}_{2} \mathrm{O}_{3}$ unit in a $\mathrm{SiO}_{2}$ network can be regarded as the introduction of two $\mathrm{AlO}_{2}$ groups (e.g., two Sisubstitutional $\mathrm{Al}$ atoms) along with an $\mathrm{O}$ vacancy (hereafter denoted $V_{O}$ ). If these "elementary particles" are assumed to be widely separated this implies either a corresponding charge separation (each substitutional $\mathrm{Al}$ carrying a negative charge taken from the $\mathrm{O}$ vacancy), or the existence of unpaired spins at the Al ions. Since the well-established EPR signal from neutral substitutional $\mathrm{Al}$ is not observed in unirradiated $\mathrm{Al}$-containing silica, it follows that charge separation must occur if this $\mathrm{Al}_{2} \mathrm{O}_{3}$ state is present. Total-energy calculations for charged impurities with periodic boundary conditions (which, as explained in the next subsection, are adopted here) are a nontrivial matter and therefore these states will not be considered here. The need for charge separation is reduced if the $\mathrm{O}$ vacancy binds to one of the $\mathrm{Al}$ atoms, and eliminated if it binds to both. I shall denote these structures $\mathrm{Al} V_{O}$ and $\mathrm{Al}_{2} V_{O}$, respectively. They are schematically depicted in Figs. 1(a), 1(b). The $\mathrm{Si}[3]$ and $\mathrm{Al}[3]$ atoms constitute electron traps due to the presence of dangling $s p^{3}$ orbitals. The $\mathrm{Al} V_{O}$ state [Fig. 1(a)] is a deep trap, since the paramagnetic configuration is the neutral one, whereas the $\mathrm{Al}_{2} V_{O}$ state is a shallow trap, since the paramagnetic state is negatively charged. In the following, the para-

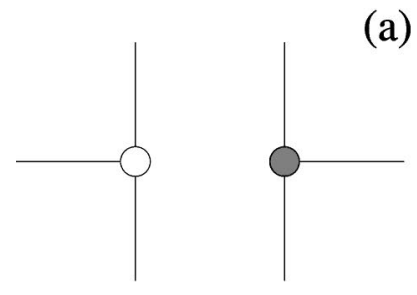

(a)
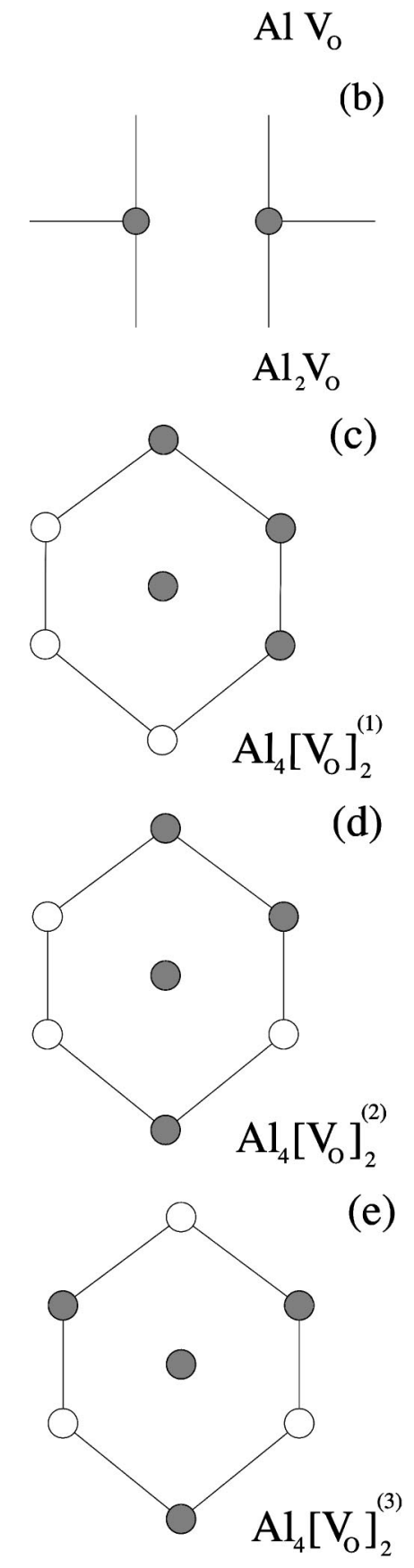

FIG. 1. Pictorial representations of the impurity states investigated. The white circles represent $\mathrm{Si}$ cations while the shaded circles represent Al. The links between cations (drawn as straight lines) proceed via two-coordinated $\mathrm{O}$ ligands which are not shown explicitly. 
magnetic states of $\mathrm{Al} V_{O}$ and $\mathrm{Al}_{2} V_{O}$ will be studied with the purpose of extracting EPR parameters.

In the unrelaxed $\alpha$-quartz structure each $\mathrm{Al}$ ion in the $\mathrm{Al}_{2} V_{O}$ state is threefold coordinated, and the state is neutral and nonmagnetic. However, although the dangling $\mathrm{Al} s p^{3}$ orbitals are unoccupied, they may still be chemically active, due to the presence of nonbonding $2 p$ orbitals on the $\mathrm{O}$ atoms in the silica network. Although the $\mathrm{O} 2 p$ levels are considerably lower in energy, the electrons in these levels may gain some hybridization energy by bonding to the empty Al $s p^{3}$ orbital. This would lead to the formation of an $\mathrm{Al}[4]$ and an $\mathrm{O}[3]$ atom in the lattice. This idea, commonly known as the "tricluster" hypothesis, was originally put forward by Lacy. ${ }^{29} \mathrm{~A}$ similar rebonding mechanism at positively charged $\mathrm{O}$ vacancies is thought to be the origin of the paramagnetic $E_{1}^{\prime}$ center in $\alpha$-quartz. ${ }^{30}$ However, the formation of the extra bond will require a distortion of the silica network with an elastic energy penalty whose magnitude will depend on the local environment.

Another structural model which has been suggested by several authors is the formation of three Si-substitutional Al ions compensated by a fourth $\mathrm{Al}^{3+}$ ion residing in the interstitial parts of the silica network. ${ }^{31-33}$ Since each substitutional $\mathrm{Al}$ ion needs an extra electron (from the interstitial $\mathrm{Al}^{3+}$ ) to fill all bonds, it is clear that there will be a strong electrostatic attraction between substitutional and interstitial ions. In fact, the energy gained by moving all four constituent ions together can be estimated as

$$
\Delta E=\frac{6 e^{2}}{\epsilon d}
$$

where $\epsilon$ is the dielectric constant of silica and $d$ is the distance between the $\mathrm{Al}$ ions. Taking $d=3 \AA$ (approximately the shortest distance between $\mathrm{Si}$ atoms in silica) and $\epsilon$ $=4.48,{ }^{34}$ one obtains $\Delta E=6.43 \mathrm{eV}$, so in the present work I will only consider the case where the interstitial $\mathrm{Al}^{3+}$ ion resides next to the substitutional Al's, a structure I shall denote as $\mathrm{Al}_{4}\left[V_{O}\right]_{2}$. Even with this restriction it is clear that there is a large number of possible variations to this structural theme, of which I will only investigate a few examples. A common feature of crystalline silica allotropes is the appearance of ring structures containing six silicon atoms, and these rings are also thought to be abundant in amorphous silica. I will therefore investigate some $\mathrm{Al}_{4}\left[V_{O}\right]_{2}$ structures in which the substitutional $\mathrm{Al}$ atoms are all present in one six-member ring. Three cases, schematically depicted in Figs. 1(c)-(e), are considered: One [Fig. 1(c)] in which all Al atoms has at least one $\mathrm{Al}$ neighbor in the ring, one [Fig. 1(d)] in which two $\mathrm{Al}$ atoms are neighbors, and finally [Fig. 1(e)] one in which the $\mathrm{Al}$ atoms are evenly distributed over the ring. In the following, these states will be denoted $\mathrm{Al}_{4}\left[V_{O}\right]_{2}^{(1)}, \mathrm{Al}_{4}\left[V_{O}\right]_{2}^{(2)}$, and $\mathrm{Al}_{4}\left[V_{O}\right]_{2}^{(3)}$, respectively.

\section{B. Computational methods}

The study of the $\mathrm{Al}$ configurations outlined in the previous subsection is performed within the framework of density-functional theory (DFT). ${ }^{35,36}$ The exchange- correlation energy is described in the approximation proposed by Perdew and Wang (PW91), ${ }^{37}$ and the resulting Kohn-Sham equations are solved in a plane-wave representation using Vanderbilt's ultrasoft pseudopotential (US-PP) scheme. ${ }^{38,39}$ Unless otherwise stated, the plane-wave expansion of the wave functions is cut off at a kinetic energy of 25 Ry, and Brillouin-zone integrations are approximated by sampling only the $\Gamma$ point. In most cases, the $\mathrm{Al}$ impurities are immersed in an $\alpha$-quartz host, which is the stable crystalline form of silica at low temperatures. In addition, a few calculations have been made using $\alpha$-cristobalite as a host material. All calculations in the $\alpha$-quartz host are done in a supercell consisting of eight elementary unit cells or $24 \mathrm{SiO}_{2}$ formula units, whereas in the case of $\alpha$-cristobalite a supercell of four elementary unit cells (16 formula units) is used. For $\alpha$-quartz, lattice parameters were fixed at the theoretical equilibrium values for pure silica as calculated within the present approach $(a=5.05 \AA, \quad c / a=1.097)$. The $\alpha$-cristobalite calculations were done at the experimental lattice constants. Full structural optimizations were performed using a conjugate-gradient algorithm searching for the nearest local minimum in configuration space. Relaxations were performed until the length of the total force vector was less than $0.15 \mathrm{eV} / \AA$, except for the $\mathrm{Al} V_{O}$ states which are only studied to extract EPR properties.

From the total-energy results obtained in the supercell calculations impurity state formation energies can be obtained from the formula

$$
\begin{aligned}
E_{i}^{\text {form }}= & E_{h}\left[x_{i h} \mathrm{SiO}_{2}: y_{i} \mathrm{Al}_{2} \mathrm{O}_{3}\right] \\
& -x_{i h} E_{h}\left[\mathrm{SiO}_{2}\right]-y_{i}\left(2 E_{a t}[\mathrm{Al}]+3 E_{a t}[\mathrm{O}]\right) .
\end{aligned}
$$

Here $i$ indexes the various impurity states $\left(\mathrm{Al}_{2} V_{O}\right.$, $\mathrm{Al}_{4}\left[V_{O}\right]_{2}^{(1)}$, etc.), while $h$ indexes the crystalline hosts ( $\alpha$-quartz and $\alpha$-cristobalite). $x_{i h}, y_{i}$ are the number of $\mathrm{SiO}_{2}$ and $\mathrm{Al}_{2} \mathrm{O}_{3}$ units in the supercell, e.g., for $\mathrm{Al}_{2} V_{O}$ in cristobalite $x=14$ and $y=1$, while for $\mathrm{Al}_{4}\left[V_{O}\right]_{2}$ in $\alpha$-quartz $x$ $=21, y=2 . E_{h}\left[\mathrm{SiO}_{2}\right]$ denotes the energy per formula unit of a pure $\mathrm{SiO}_{2}$ supercell calculated with same parameters for lattice constants, plane-wave cutoff, k-point sampling, etc. $E_{a t}[\mathrm{Al}], E_{a t}[\mathrm{O}]$ is the energy of free $\mathrm{Al}, \mathrm{O}$ atoms. The choice of reference state is of no consequence in the present paper since only formation energy differences will be relevant (it is not my intention to model the glass formation process). The computation of absolute formation energies, whether using free-atom or crystalline reference energies, is prone to errors from basis-set cutoff, k-point sampling and the finite size of the supercell. However, in the formation energy differences these errors cancel to a large extent.

The calculation of hyperfine parameters and electric-field gradient tensors require knowledge of the wave function close to, or even right at, the nucleus, which appears to present a problem, as the pseudopotentials do not describe the wave function correctly in this region of space. To overcome this problem, I reconstruct the true wave function in the core region by augmenting the pseudo wave function along the lines described in Ref. 40. Using this procedure, one obtains a wave function very similar to that of the 
projector-augmented wave (PAW) scheme introduced by Blöchl, ${ }^{41,42}$ which has been shown to give rather accurate results for the properties of interest here. ${ }^{43-45}$ The Al ultrasoft pseudopotential used throughout has two projector functions in the $s$ channel and one in the $p$ and $d$ channels. For the isotropic part of the hyperfine tensor, core-polarization effects are approximately taken into account by recalculating the core states while keeping the spin-polarized valence electron density fixed. This is not an exact approach, as it ignores the back reaction of the core spin polarization on the valence electron density, but it serves to give an idea of the magnitude of the core-polarization effect. In the present case, corepolarization was found to affect the isotropic hyperfine parameters by about $1 \%$ in all calculations.

To estimate Al core-level shifts new Al pseudopotentials with a hole present in either the $1 s$ or $2 p$ channel were constructed. One $\mathrm{Al}$ atom in the supercell is then described by such a potential while the total-number of electrons is kept equal to that of the neutral cell without core holes. The total-energy difference between $1 s$ and $2 p$ hole states provides a measure of the core-valence interaction contribution to the $K_{\alpha}$ transition energy, and can thereby be used to deduce chemical shifts. It has recently been demonstrated that this approach is able to predict chemical shifts of $\mathrm{Al}, \mathrm{Si}$, and Ge lines in various oxide compounds to an accuracy of $10 \%$ or better, ${ }^{11}$ and it therefore appears suitable for predicting line positions in the present problem. In the same way, the total-energy difference between states with a $1 s$ (or $2 p$ ) hole in different positions provides a measure of the chemical shift of this core level between the two $\mathrm{Al}$ atoms in question. No attempt at calculating absolute transition energies is made. Core-level shifts of $\mathrm{O} 1 \mathrm{~s}$ levels are calculated in a similar way, introducing an $\mathrm{O}$ pseudopotential with a hole in the $1 \mathrm{~s}$ shell at the $\mathrm{O}$ atoms of interest while keeping the number of valence electrons fixed. By comparing totalenergy values with the $1 s$ hole in different positions corelevel shifts between "ordinary" silica $\mathrm{O}$ atoms and those in the vicinity of the $\mathrm{Al}$ impurities can be deduced.

The treatment of charged states in a supercell approach is a delicate problem, since the long range of the Coulomb potential leads to a divergency in the electrostatic energy when the charged impurity is periodically repeated. For the treatment of the $\left[\mathrm{Al}_{2} V_{O}\right]^{-}$state, I shall adopt the common solution of adding a uniform background charge to eliminate the divergency. This implies a substantial error in the total energy, and possibly also minor errors in the equilibrium structures. However, for estimating the magnitudes of hyperfine coupling constants, which is the main reason for including this state here, the approach should be acceptable.

\section{NUMERICAL RESULTS}

\section{A. Geometries and electronic structures}

\section{1. $A l V_{O}$}

The neutral $\mathrm{Al} V_{O}$ state has an unpaired spin, and therefore cannot exist in appreciable quantities in ordinary silica, as its EPR activity would otherwise have been noticed. The reason for including it in the present study is to investigate its EPR properties. If charged $\mathrm{Al} V_{O}$ units exist in the normal state of silica it should be possible to observe the EPR signals from neutral $\mathrm{Al} V_{O}$ states induced upon irradiation of the material. Since accurate total-energy data are not required for this Al state the structural relaxations have not been performed as thoroughly as for the other states studied. Relaxations have been terminated when the length of the total force vector was below $0.3 \mathrm{eV} / \AA$, and have mostly been performed without spin polarization.

The $\mathrm{O}$ vacancy in pure silica has been the subject of several theoretical studies in recent years. ${ }^{46,30,45}$ It has been found that the neutral $\mathrm{O}$ vacancy in $\alpha$-quartz has one stable geometry where the dangling orbitals on the Si atoms hybridize to each other, and the distance between the two Si atoms sharing the vacancy becomes around 2.4-2.5 $\AA$. The positively charged $\mathrm{O}$ vacancy, on the other hand, has two metastable minima separated by an energy barrier. One minimum is similar to the neutral structure, with only one electron in the $\mathrm{Si}$-Si bond, which expands to about $3 \AA$. In the other, this electron localizes on one $\mathrm{Si}$ atom, whereas the second $\mathrm{Si}$ atom is displaced and its dangling orbital rebonds with the nonbonding $2 p$ state of a neighboring $\mathrm{O}$ atom. In the $\alpha$-quartz structure, the two $\mathrm{Si}$ atoms sharing an $\mathrm{O}$ vacancy are not equivalent since the bond lengths to the $\mathrm{O}$ atom that was removed are slightly different. Only the long-bonded $\mathrm{Si}$ atom has a stable rebonded configuration. This configuraion is commonly known as the silica $E_{1}^{\prime}$ center. Concerning the relative stability of the two states somewhat different results have been found using different theoretical approaches. Using the PAW technique and a generalized gradient approximation (GGA) energy functional Blöchl found that the two states were almost degenerate with an energy difference of only $0.04 \mathrm{eV}$ (the rebonded state having the lower energy), Boero et al. reported a $0.3-\mathrm{eV}$ difference from US-PP calculations within the local-density approximation (LDA), whereas the Hartree-Fock cluster calculations of Pacchioni and Ieranò yielded an energy difference of $0.64 \mathrm{eV}^{46}$

When one of the cations sharing the $\mathrm{O}$ vacancy is an $\mathrm{Al}$ atom, the electronic structure of the neutral defect is similar to that of the positively charged $\mathrm{O}$ vacancy in pure silica, since $\mathrm{Al}$ has one valence electron less than $\mathrm{Si}$. Therefore one may expect that also the energy landscape of the neutral $\mathrm{Al} V_{O}$ state will resemble that of the positively charged $\alpha$-quartz $\mathrm{O}$ vacancy. I have used the equilibrium geometries for the pure-silica vacancy as starting points for the structural relaxations of the $\operatorname{Al} V_{O}$ states, substituting one of the $\mathrm{Si}$ cations with Al. Since in each of the two stable geometries of the charged $\mathrm{Si}-\mathrm{Si}$ vacancy there are two inequivalent $\mathrm{Si}$ cations to substitute there are in principle four possible states to consider. In two of them, both the $\mathrm{Si}$ and $\mathrm{Al}$ cations will bond to only three $\mathrm{O}$ atoms. Since the hyperfine parameters for $\mathrm{Si}$ and $\mathrm{Al}$ must be expected to be very similar (except for the directionality of the anisotropic tensor) in these two cases only one (with $\mathrm{Al}$ at the short-bonded site) will be treated here. On the other hand, when one of the cations is rebonded, it is important for the spin distribution, and therefore the hyperfine parameters, whether the rebonded cation is $\mathrm{Si}$ or Al. Therefore both these cases have been investigated. All the relaxed $\mathrm{Al} V_{O}$ geometries are shown in Fig. 2, with bond 

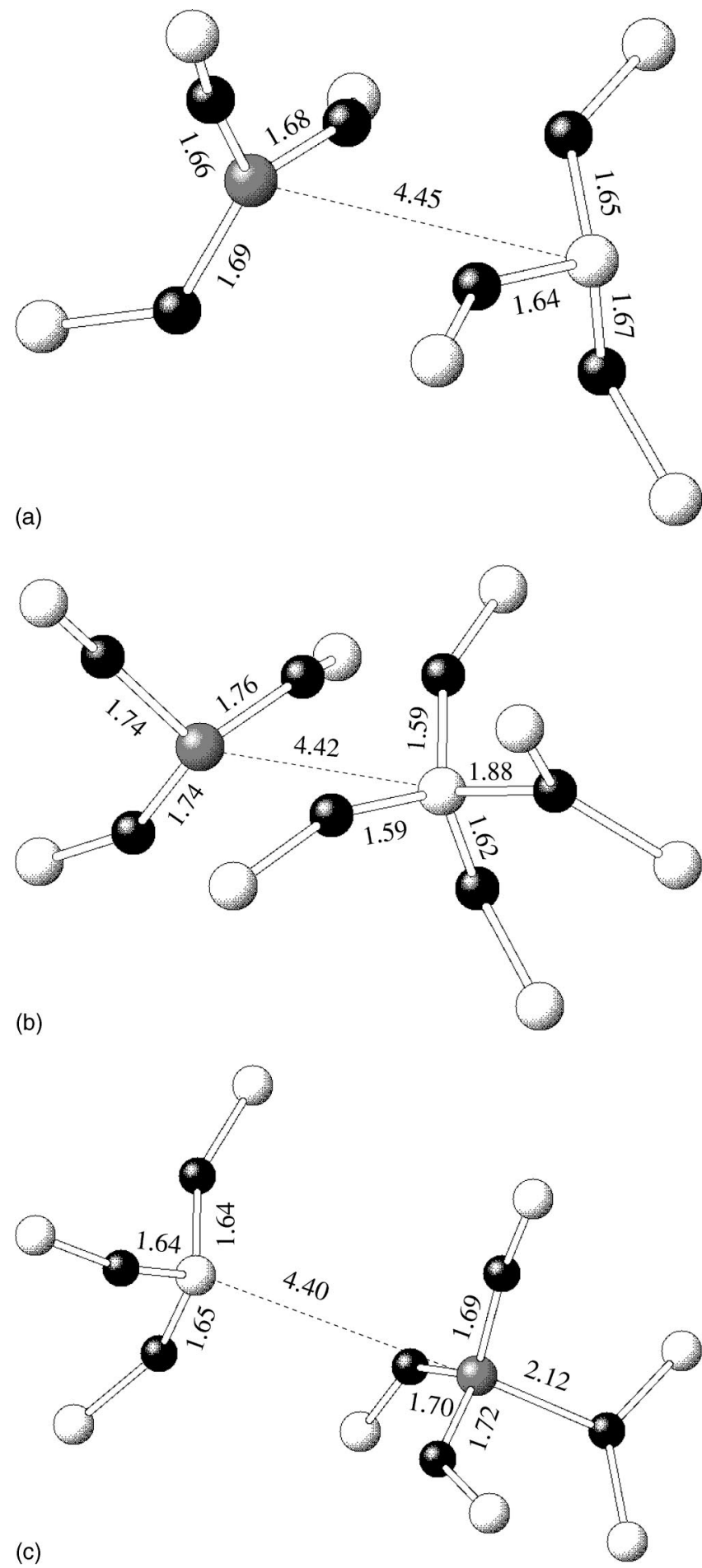

FIG. 2. Relaxed geometries of the various $\mathrm{Al} V_{O}$ states considered. White spheres are $\mathrm{Si}$ atoms, gray spheres $\mathrm{Al}$, and black spheres $\mathrm{O}$. (a) $\mathrm{Al}[3], \mathrm{Si}[3]$ with $\mathrm{Al}$ on the short-bonded side of the $\mathrm{O}$ vacancy. (b) $\mathrm{Al}[3], \mathrm{Si}[4]$, cation sites as in (a). (c) $\mathrm{Si}[3], \mathrm{Al}[4]$ with cation sites interchanged relative to (a) and (b). Some bond lengths are given in $\AA$.

lengths in $\AA$. Judging from the spin-density distribution and in particular the hyperfine parameters (to be discussed in Sec. III C), the unpaired electron does not localize strongly on the Al cation in any of the structures considered. In fact, in the nonrebonded geometry the electron is almost completely localized on $\mathrm{Si}$, and the distance between the cations is $\sim 4.45 \AA$, suggesting that $\mathrm{Si}-\mathrm{Al}$ hybridization does not play an appreciable role in determining the structure. This is in contrast to the situation at a $\mathrm{Si}-\mathrm{Si}$ vacancy, where the $\mathrm{Si}-\mathrm{Si}$ distance in the positive charge state is about $3 \AA$ and appreciable $\mathrm{Si}$-Si hybridization remains. The highest spin density on the Al site is found for the state in Fig. 2(b) with rebonded $\mathrm{Si}$, as expected. In this state, the unpaired spin is rather delocalized, with appreciable weigth on both $\mathrm{Al}, \mathrm{Si}$, and in the interstitial region.

The tendency of the unpaired electron to localize on $\mathrm{Si}$ rather than $\mathrm{Al}$ is a consequence of the fact that the $s p$ levels on $\mathrm{Si}$ are lower in energy than those on Al. The total energies for the various $\mathrm{AlV}_{O}$ states also reflect this fact: The state in Fig. 2(c) with rebonded Al is about $1.3 \mathrm{eV}$ lower in energy than that with rebonded Si [Fig. 2(b)], and $\sim 0.5 \mathrm{eV}$ lower than the state without rebonding. This is because a structure with the unpaired spin present in the low-energy Si $s p$ orbitals is preferred. The energy of the structure in Fig. 2(c) is then further lowered compared to that of Fig. 2(a) by the formation of an extra Al-O bond. It is interesting to note, however, that this bond is weaker (judging from the bond length) than the corresponding Si-O bond in Fig. 2(b). This suggests that, if the unpaired spin is removed, so that a positively charged $\mathrm{Al} V_{O}$ state is formed, it will be favorable to have $\mathrm{Si}$ rather than $\mathrm{Al}$ at the rebonded site. Therefore if neutral $\mathrm{A} 1 V_{O}$ states observed in irradiated samples are assumed to be formed from positively charged precursors it is possible that the state in Fig. 2(b) will be present, although metastable, in spite of its higher energy.

\section{2. $A l_{2} V_{O}$ and $\left[\mathrm{Al}_{2} \mathrm{~V}_{O}\right]^{-}$}

When two $\mathrm{Al}$ atoms share an $\mathrm{O}$ vacancy the electronic structure is similar to that of a doubly charged $\mathrm{O}$ vacancy in pure silica. Since no electrons need to be accommodated in the dangling cation orbitals, one would a priori expect both $\mathrm{Al}$ atoms to rebond in the manner discussed in the previous section. Indeed, it is found that the nonrebonded energy minimum goes away, but I have not been able to find any stable configuration in which the short-bonded $\mathrm{Al}$ atom forms an additional bond. Thus, as can be seen from Fig. $3(\mathrm{a})$, in the equilibrium geometry there is one $\mathrm{Al}[3]$ atom and one $\mathrm{Al}[4]$ with a somewhat stretched fourth bond. This finding is very important, since it shows that the rebonding happens at the expense of lattice distortion energy, and therefore is dependent on a favorable local environment. The Al-Al distance in the relaxed state is $4.82 \AA$, suggesting that no chemical interaction between the $\mathrm{Al}$ ions is present. This would indeed be unexpected given that both the dangling $\mathrm{Al}$ orbitals are empty. The implications of these results for the possible states of $\mathrm{Al}$ in amorphous silica will be discussed below.

In order to investigate the dependence of the rebonding mechanism on the local environment, the $\mathrm{Al}_{2} V_{O}$ configuration was also studied within an $\alpha$-cristobalite host, as described in Sec. II B. In contrast to the case of $\alpha$-quartz two local minima were found in the $\alpha$-cristobalite host, one similar to the rebonded state in $\alpha$-quartz, with a bond length of 

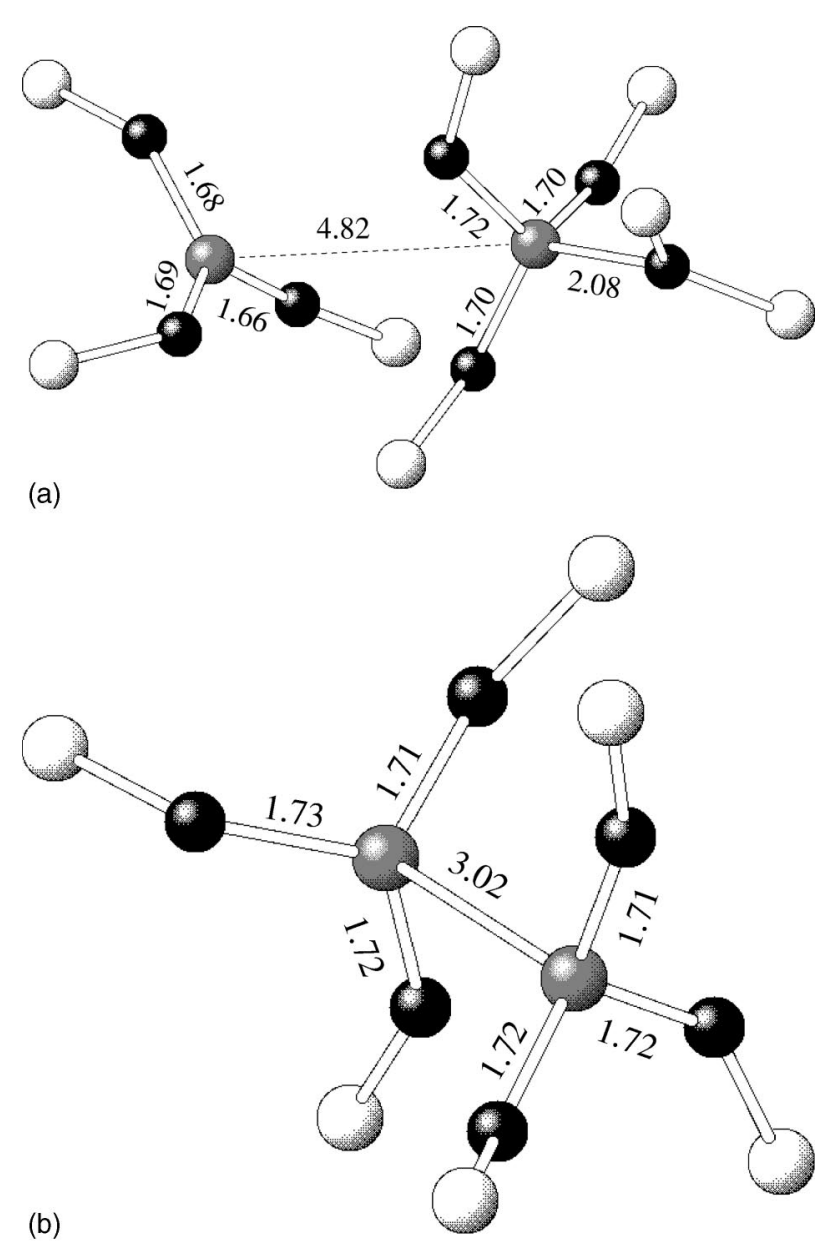

FIG. 3. Relaxed geometries of the $\mathrm{Al}_{2} V_{O}$ (a) and $\left[\mathrm{Al}_{2} V_{O}\right]^{-}$ (b) states. Symbols and units as in Fig. 2.

$2.05 \AA$ for the extra Al-O bond, and another metastable state in which this distance had expanded to $2.75 \AA$, so that both $\mathrm{Al}$ ions could be considered to be in the $\mathrm{Al}[3]$ state.

The dangling orbital on the $\mathrm{Al}[3]$ atom constitute a localized state in the silica band gap and can as such act as an electron trap. EPR evidence of such trapped electrons was reported by Brower. ${ }^{12,13}$ To investigate the EPR properties of this trap I have performed DFT calculations for the negatively charged $\mathrm{Al}_{2} V_{O}$ state, $\left[\mathrm{Al}_{2} V_{O}\right]^{-}$, in the $\alpha$-quartz host. If the electron is added to the neutral equilibrium geometry without structural relaxation it is indeed found to localize on the $\mathrm{Al}[3]$ atom. This structure is not stable, but relaxes into a state in which the Al ions bond to each other, and the unpaired spin is evenly distributed over both Al sites. The equilibrium geometry is shown in Fig. 3(b). The Al-Al distance of $3.02 \AA$ is similar to what was found for the Si-Si bond length at a positively charged $\mathrm{O}$ vacancy in pure silica by Blöchl.

\section{3. $A l_{4}\left[V_{O}\right]_{2}$}

When the $\mathrm{Al}_{4}\left[V_{O}\right]_{2}$ structures schematically shown in Fig. 1(b) are released they all stabilize in geometries where the $\mathrm{Al}$ ions initially substituting for $\mathrm{Si}$ in the silica network stay four coordinated although with some degree of disper- sion in the bond lengths. The behavior of the interstitial $\mathrm{Al}$ ion is state dependent. In the $\mathrm{Al}_{4}\left[V_{O}\right]_{2}^{(1)}$ and $\mathrm{Al}_{4}\left[V_{O}\right]_{2}^{(3)}$ geometries, the interstitial $\mathrm{Al}$ relaxes into a five-coordinated position, whereas in the $\mathrm{Al}_{4}\left[V_{O}\right]_{2}^{(2)}$ state it ends up being four coordinated, with bond lengths similar to the substitutional $\mathrm{Al}$ ions. The geometries are shown in Fig. 4. For the sake of clarity, only the atoms in the Al-containing sixmember ring, the interstitial $\mathrm{Al}$ and its nearest neighbors have been included. It should be noted that all the $\mathrm{O}$ atoms bonded to the interstitial $\mathrm{Al}$ are three coordinated although some of them do not appear as such in the figure because they are bonded to $\mathrm{Si}$ atoms outside the ring. The mean and variance of the bond lengths for the first and second coordination shells are given in Table I along with the extended $\mathrm{x}$-ray-absorption fine-structure (EXAFS) results recently reported by Sen. ${ }^{14}$ The agreement between theory and experiment is quite good, especially for the bond lengths. In the second neighbor shell both coordination numbers and the mean-square deviation of the bond lengths are somewhat overestimated by the theory. In this connection it should be noted that these parameters are correlated in the EXAFS data analysis, and can be increased/decreased simultaneously over some finite range without compromising the quality of the fit to the raw data (Sen estimates an uncertainty of \pm 1 for the coordination number). However, from the total-energy results to be presented in the next subsection it can be seen that low bond length dispersion seems to correlate with low total energy. It is therefore to be expected that the present supercell model, with its limited degrees of freedom for structural relaxation, will overestimate the bond length dispersion in an amorphous silica network. On the other hand, the secondshell coordination number is more or less dictated by the structural model: The substitutional $\mathrm{Al}$ ions have four $\mathrm{Si} / \mathrm{Al}$ second-nearest neighbors in the silica network and are, in addition, close to the interstitial Al giving a second-shell coordination of 5. Only in the second shell of the interstitial ion some variations in coordination number between different structures is seen.

Considering the nature of the $\mathrm{O}$ linkages it is interesting to notice that no $\mathrm{O}[2]$ species bonded to two $\mathrm{Al}$ ions (Al$\mathrm{O}-\mathrm{Al}$ links) are found, in spite of the proximity of the four $\mathrm{Al}$ ions. Most of the $\mathrm{O}[3]$ species are bonded to two $\mathrm{Al}$ and one $\mathrm{Si}$ atom, however, $\mathrm{O}$ atoms with three $\mathrm{Al}$ neighbors are found in the $\mathrm{Al}_{4}\left[V_{O}\right]_{2}^{(1)}$ and $\mathrm{Al}_{4}\left[V_{O}\right]_{2}^{(2)}$ structures and one $\mathrm{O}[3]$ atom with two Si neighbors is found in $\mathrm{Al}_{4}\left[V_{O}\right]_{2}^{(2)}$.

\section{B. Total energies and thermodynamics}

The formation energies calculated for the various $\mathrm{Al}_{2} \mathrm{O}_{3}$ geometries are given in Table II. All energies are per $\mathrm{Al}_{2} \mathrm{O}_{3}$ unit and are measured relative to the $\mathrm{Al}_{4}\left[V_{O}\right]_{2}^{(2)}$ state, which is lowest in energy. Considering first the results obtained in the $\alpha$-quartz supercell, the $\mathrm{Al}_{4}\left[V_{O}\right]_{2}^{(2)}$ and $\mathrm{Al}_{4}\left[V_{O}\right]_{2}^{(3)}$ states are seen to be nearly degenerate in energy, while the $\mathrm{Al}_{4}\left[V_{O}\right]_{2}^{(1)}$ is slightly less favorable. However, all $\mathrm{Al}_{4}\left[V_{O}\right]_{2}$ configurations are clearly favored over the $\mathrm{Al}_{2} V_{O}$ state. This is no surprise, given that there are $\sim$ eight $\mathrm{Al}-\mathrm{O}$ bonds per $\mathrm{Al}_{2} \mathrm{O}_{3}$ unit in the $\mathrm{Al}_{4}\left[V_{O}\right]_{2}$ states compared to seven in the $\mathrm{Al}_{2} V_{O}$ geometry, and that one of the bonds in the latter is 


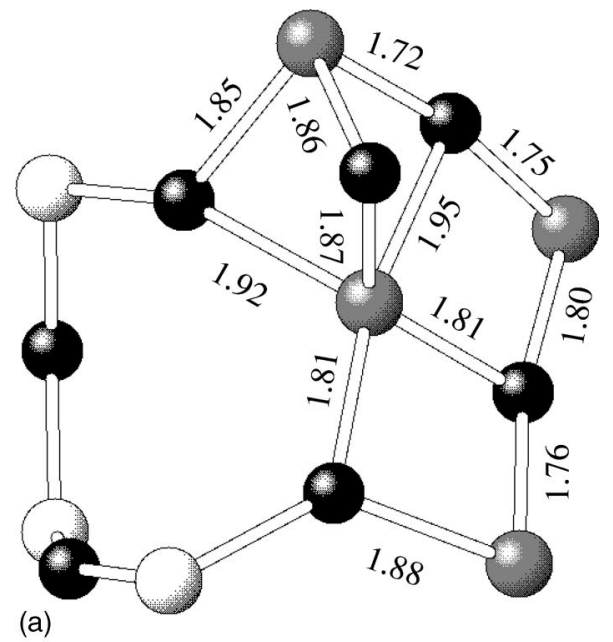

(a)
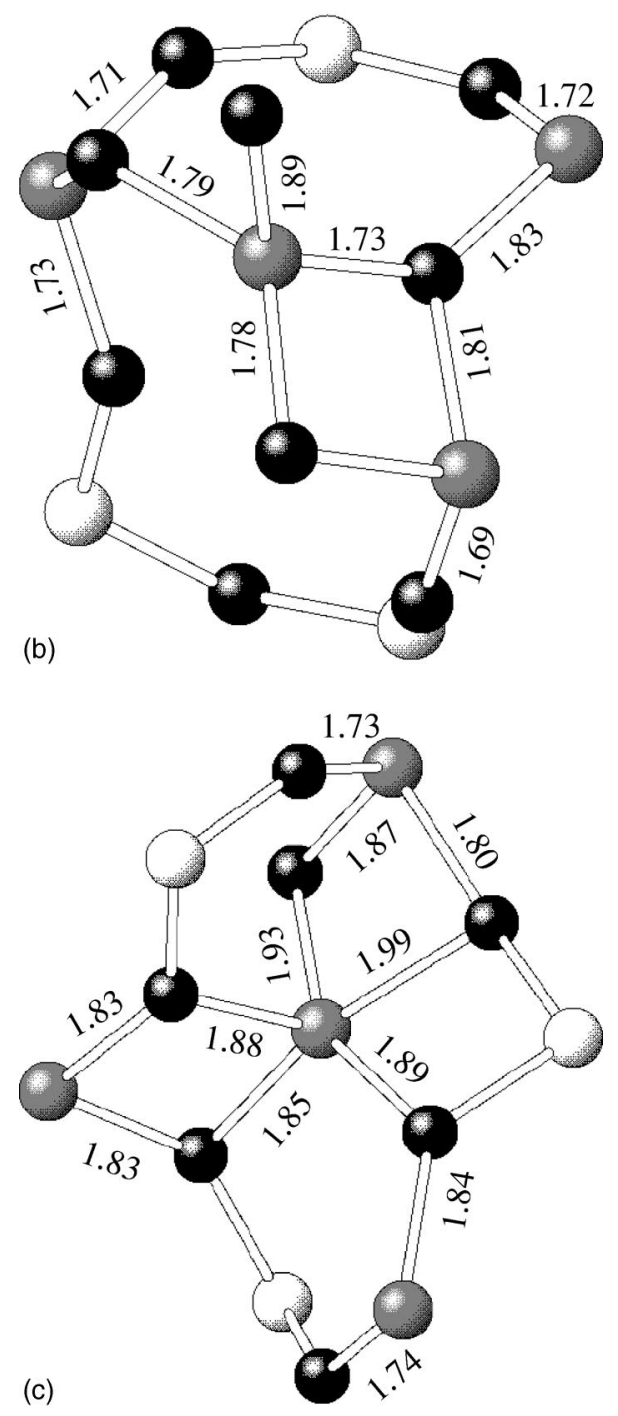

FIG. 4. Relaxed geometries of the $\mathrm{Al}_{4}\left[V_{O}\right]_{2}^{(1)}$ (a), $\mathrm{Al}_{4}\left[V_{O}\right]_{2}^{(2)}$ (b), and $\mathrm{Al}_{4}\left[V_{O}\right]_{2}^{(3)}$ (c) states. Symbols and units as in Figs. 2 and 3.

weak. The energy gained from forming the seventh Al-O bond in $\mathrm{Al}_{2} V_{O}$ can be estimated from the results obtained in the $\alpha$-cristobalite structure, where two local minima were found, one of which (denoted $\mathrm{Al}_{2} V_{O}^{(2)}$ in Table I) practically
TABLE I. Local structural parameters averaged over the $\mathrm{Al}$ ions in the various $\mathrm{Al}_{4}\left[V_{O}\right]_{2}$ impurity states considered. Coordination numbers $(Z)$, bond lengths $(d)$, and mean-square deviation of bond lengths $\left(\sigma^{2}\right)$ are given for the first and second neighbor shell (consisting, respectively, of $\mathrm{O}$ and $\mathrm{Si} / \mathrm{Al}$ atoms). Units are $\AA$ and $\AA^{2}$.

\begin{tabular}{lcccccc}
\hline \hline System & $Z_{1}$ & $d_{1}$ & $\sigma_{1}^{2}$ & $Z_{2}$ & $d_{2}$ & $\sigma_{2}^{2}$ \\
\hline $\mathrm{Al}_{4}\left[V_{O}\right]_{2}^{(1)}$ & 4.25 & 1.79 & 0.007 & 5.25 & 3.06 & 0.127 \\
$\mathrm{Al}_{4}\left[V_{O}\right]_{2}^{(2)}$ & 4 & 1.77 & 0.006 & 5.25 & 3.11 & 0.048 \\
$\mathrm{Al}_{4}\left[V_{O}\right]_{2}^{(3)}$ & 4.25 & 1.80 & 0.008 & 5.5 & 3.08 & 0.057 \\
Expt. (Ref. 14) & 4 & 1.77 & 0.004 & 4 & 3.12 & 0.024 \\
\hline \hline
\end{tabular}

has two $\mathrm{Al}[3]$ ions. In the cristobalite structure the gain is only $0.1 \mathrm{eV}$, whereas the formation energy of $\mathrm{Al}_{2} V_{O}$ in $\alpha$-quartz is $0.44 \mathrm{eV}$ lower than that of the metastable $\mathrm{Al}_{2} V_{O}$ state in the cristobalite host. Since the length of the stretched bond is similar in the two hosts (the seventh bond in cristobalite is actually slightly shorter than that in $\alpha$-quartz) it is clear that differences in the elastic energy cost of lattice deformation plays a considerable role in determining these energy gains. In the present case, the energy difference between the different hosts may, at least in part, be caused by the fact that the supercell used is larger for $\alpha$-quartz than for $\alpha$-cristobalite, thus providing more degrees of freedom for the structural relaxations.

Since the formation of $\mathrm{Al}_{4}\left[V_{O}\right]_{2}$ structures requires two $\mathrm{Al}_{2} \mathrm{O}_{3}$ units, the $\mathrm{Al}_{2} V_{O}$ state, although disfavored from totalenergy considerations alone, will be favored by entropy effects. A full simulation of finite-temperature equilibrium thermodynamics is beyond the scope of the present work, and might not even be relevant for all types of glass. However, it is interesting to consider a few simplified thermodynamical models in order to shed light on the implications of the total-energy results quoted above. It should, of course, be stressed that the results obtained for impurity state concentrations are order-of-magnitude estimates rather than accurate quantitative predictions.

Considering the $\mathrm{Al}_{2} \mathrm{O}_{3}$ units to be moving in a fully polymerized silica network the transformation between the two main impurity models investigated here can be written as the reaction

$$
2 \mathrm{Al}_{2} V_{O} \rightleftharpoons \mathrm{Al}_{4}\left[V_{O}\right]_{2} .
$$

TABLE II. Formation energies (relative to the $\mathrm{Al}_{4}\left[V_{O}\right]_{2}^{(2)}$ state) for the various $\mathrm{Al}$ impurity states considered here, as calculated from Eq. (2).

\begin{tabular}{lcc}
\hline \hline System & Host & $E^{\text {form }} / \mathrm{Al}_{2} \mathrm{O}_{3}(\mathrm{eV})$ \\
\hline $\mathrm{Al}_{2} V_{O}$ & $\alpha$-quartz & 1.40 \\
$\mathrm{Al}_{2} V_{O}^{(1)}$ & $\alpha$-crist. & 1.73 \\
$\mathrm{Al}_{2} V_{O}^{(2)}$ & $\alpha$-crist. & 1.84 \\
$\mathrm{Al}_{4}\left[V_{O}\right]_{2}^{(1)}$ & $\alpha$-quartz & 0.23 \\
$\mathrm{Al}_{4}\left[V_{O}\right]_{2}^{(2)}$ & $\alpha$-quartz & 0 \\
$\mathrm{Al}_{4}\left[V_{O}\right]_{2}^{(3)}$ & $\alpha$-quartz & 0.04 \\
\hline \hline
\end{tabular}


Neglecting the contributions from vibrational entropy and impurity interactions, the Helmholz free energy of the impurities may be written in the form

$$
\begin{gathered}
F=\sum_{i} F_{i}, \\
F_{i}=-k T N_{i}\left(\ln \zeta_{i}-\ln N_{i}+1\right), \\
\zeta_{i}=\sum_{s} \exp \left(-\frac{\varepsilon(s)}{k T}\right) .
\end{gathered}
$$

Here $i$ indexes the $\mathrm{Al}$ complexes $\mathrm{Al}_{2} V_{O}, \mathrm{Al}_{4}\left[V_{O}\right]_{2}, s$ denotes the various possible states of a given complex, and $\varepsilon(s)$ denotes the energy of state $s$. From this expression one can derive the law of mass action

$$
\frac{N_{\mathrm{Al}_{4}\left[V_{O}\right]_{2}}}{N_{\mathrm{Al}_{2} V_{O}}^{2}}=\frac{\zeta_{\mathrm{Al}_{4}\left[V_{O}\right]_{2}}}{\zeta_{\mathrm{Al}_{2} V_{O}}^{2}} .
$$

The state sums in the $\zeta$ parameters should now include all possible states of a given composition. For the $\mathrm{Al}_{2} V_{O}$ " ecule" there is obviously one possible state for each $\mathrm{O}$ site in the lattice, so that

$$
\zeta_{\mathrm{Al}_{2} V_{O}}=2 N_{l a t} \exp \left(-\frac{\varepsilon\left(\mathrm{Al}_{2} V_{O}\right)}{k T}\right),
$$

where $N_{\text {lat }}$ is the number of cation sites in the lattice (i.e., in the limit of low $\mathrm{Al}$ concentration $N_{\text {lat }} \approx N_{S i}$ ). For the various $\mathrm{Al}_{4}\left[V_{O}\right]_{2}$ states I shall assume that all structures having the schematic form depicted in Fig. 1(b) are degenerate, and similar for the structures in Figs. 1(c) and 1(d). Only these $\mathrm{Al}_{4}\left[V_{O}\right]_{2}$ geometries will be included in the calculation. This is obviously an oversimplification and probably means that the results provide a lower bound on the $\mathrm{Al}_{4}\left[V_{O}\right]_{2}$ abundance since not all relevant $\mathrm{Al}_{4}\left[V_{O}\right]_{2}$ geometries are taken into account. In $\alpha$-quartz there is one six-member ring per cation site, so the expression for $\zeta_{\mathrm{Al}_{4}\left[V_{O}\right]_{2}}$ now becomes

$$
\zeta_{\mathrm{Al}_{4}\left[V_{O}\right]_{2}}=N_{\text {lat }} \sum_{i=1}^{3} x_{i} \exp \left(\frac{-\varepsilon\left(\mathrm{Al}_{4}\left[V_{O}\right]_{2}\right]^{(i)}}{k T}\right)
$$

with $x_{1}=6, x_{2}=12, x_{3}=2$. Equation (7) may then be cast in the form

$$
\begin{gathered}
\frac{c_{\mathrm{Al}_{4}\left[V_{O}\right]_{2}}}{c_{\mathrm{Al}_{2} V_{O}}^{2}}=\exp \left(\frac{2 E_{\mathrm{Al}_{2} V_{O}}}{k T}\right) \sum_{i=1}^{3} x_{i} \exp \left(-\frac{E_{\mathrm{Al}_{4}\left[V_{O}\right]_{2}}^{(i)}}{k T}\right), \\
c_{i}=\frac{N_{i}}{N_{\text {lat }}},
\end{gathered}
$$

where the energy parameters may now be read off from Table II. This formula, together with the requirement that all available $\mathrm{Al}$ ions are present in either $\mathrm{Al}_{2} V_{O}$ or $\mathrm{Al}_{4}\left[V_{O}\right]_{2}$ states can then be used to determine the fraction of $\mathrm{Al}$ ions present in each kind of state at a given temperature and $\mathrm{Al}_{2} \mathrm{O}_{3}$ concentration. In Fig. 5(a) the results for temperatures

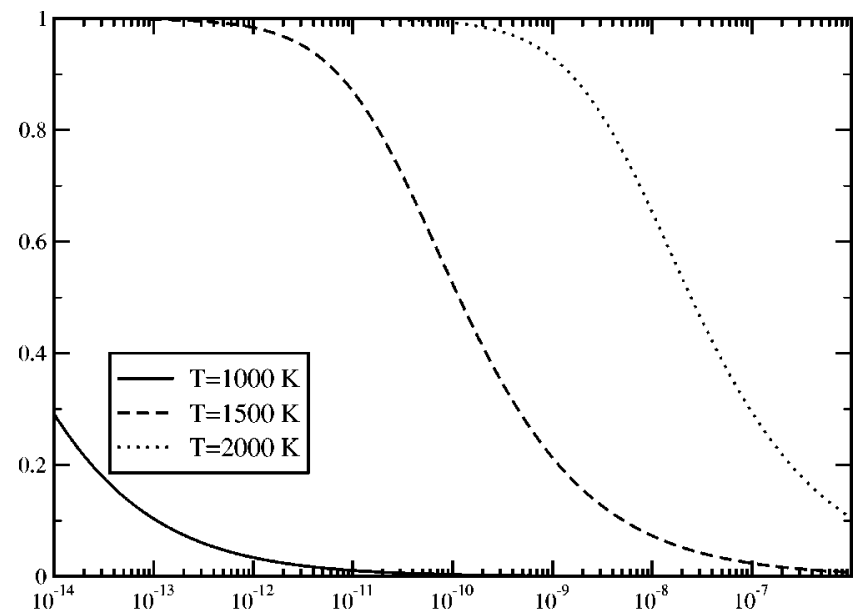

(a) $\quad \mathrm{Al}_{2} \mathrm{O}_{3}$ concentration
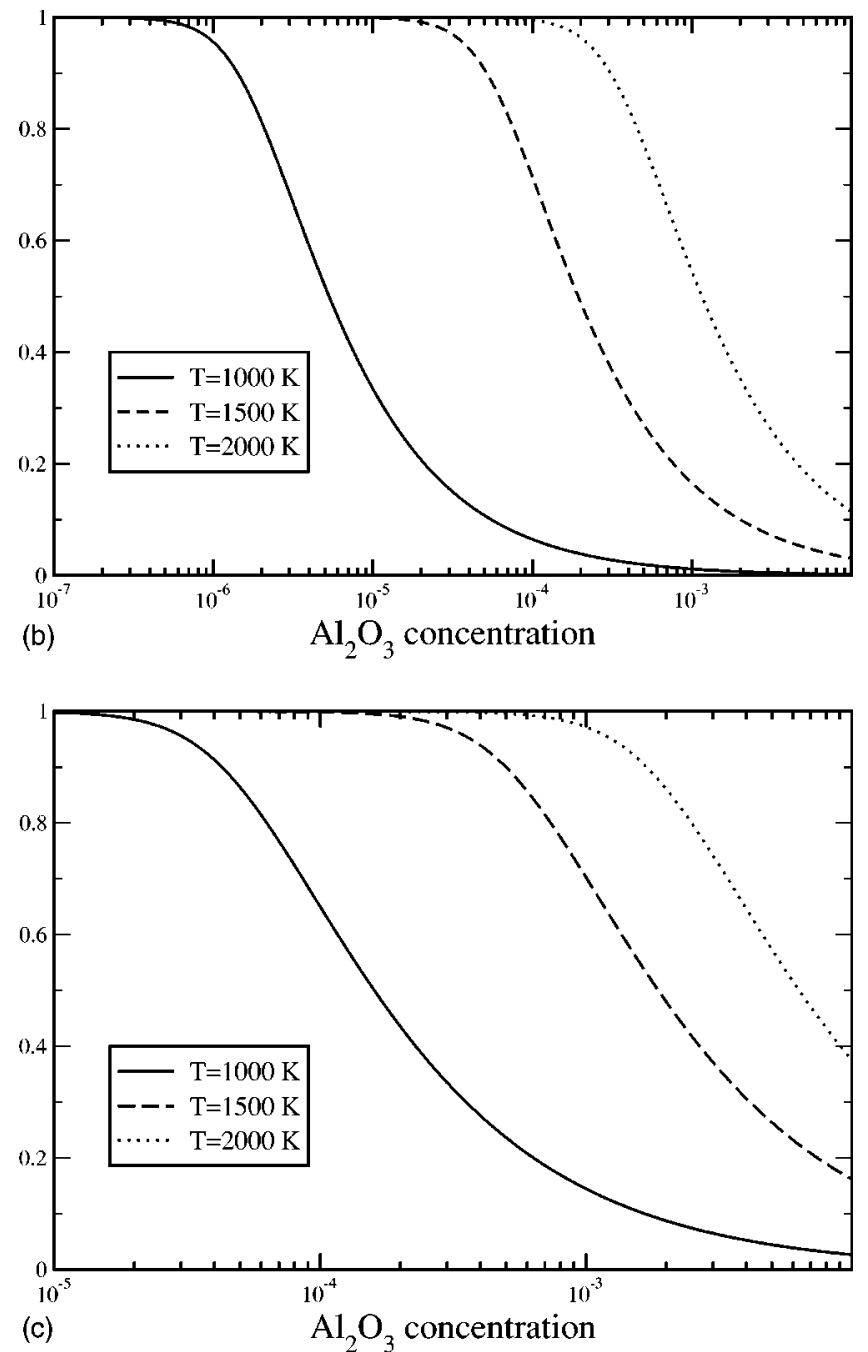

FIG. 5. Fraction of $\mathrm{Al}$ ions in the $\mathrm{Al}_{2} V_{O}$ state as a function of $\mathrm{Al}_{2} \mathrm{O}_{3}$ concentration and temperature for various assumptions about $\mathrm{Al}_{2} V_{O}$ properties in the amorphous state of silica. (a) $\mathrm{Al}$ ions in the $\mathrm{Al}_{2} V_{O}$ state are paired. (b) $\mathrm{Al}$ ions in the $\mathrm{Al}_{2} V_{O}$ state move independently in the lattice. (c) Same as (b) with a lower energy estimate for the independent $\mathrm{Al}$ ions (see text for explanation). 
of 1000,1500 , and $2000 \mathrm{~K}$ are plotted. It can be seen that the $\mathrm{Al}_{4}\left[V_{O}\right]_{2}$ states are completely dominant for all $\mathrm{Al}_{2} \mathrm{O}_{3}$ concentrations of practical interest (natural quartz usually contains $\mathrm{Al}$ impurities in the ppm range), even at the highest temperatures. This seems to rule out the presence of $\mathrm{Al}_{2} V_{O}$ units in $\alpha$-quartz (which has actually transformed into $\beta$-quartz at these high temperatures), unless the crystal is far from thermodynamic equilibrium. On the other hand, the results do not necessarily imply the predominance of $\mathrm{Al}_{4}\left[V_{O}\right]_{2}$ structures since states in which the $\mathrm{O}$ vacancy is separated from one or more of the $\mathrm{Al}$ ions have not been considered here. Although these states are likely to be still higher in energy they will be favored by entropy considerations at sufficiently low concentrations.

Since the two $\mathrm{Al}$ ions in the $\mathrm{Al}_{2} V_{O}$ structure are only connected structurally (they share an $\mathrm{O}$ vacancy) one can speculate that they might be free to move away from each other in an amorphous silica host where the concept of an $\mathrm{O}$ vacancy is not so well defined. This is in contrast to the $\mathrm{Al}_{4}\left[V_{O}\right]_{2}$ states, which are kept together by electrostatic forces as argued in Sec. II A. The simplest and most radical assumption is completely independent motion of the $\mathrm{Al}$ ions. In this case Eq. (10) is replaced by

$$
\frac{c_{\mathrm{Al}_{4}\left[V_{O}\right]_{2}}}{c_{A l}^{4}}=\exp \left(\frac{2 E_{\mathrm{Al}_{2} V_{O}}}{k T}\right) \sum_{i=1}^{3} x_{i} \exp \left(-\frac{E_{\mathrm{Al}_{4}\left[V_{O}\right]_{2}}^{(i)}}{k T}\right),
$$

$c_{A l}$ being the concentration of isolated $\mathrm{Al}$ ions. The resulting fraction of $\mathrm{Al}$ ions in this state is plotted in Fig. 5(b) for the same temperatures as in Fig. 5(a). The splitting of the $\mathrm{Al}_{2} V_{O}$ state is seen to greatly disfavor the formation of $\mathrm{Al}_{4}\left[V_{O}\right]_{2}$ complexes, so that the independent $\mathrm{Al}$ ions are now expected to be dominant in the 10-100-ppm concentration range usually found in glass made from natural quartz samples. On the other hand, the $\mathrm{Al}_{4}\left[V_{O}\right]_{2}$ state is still dominant for the high end of the concentration range investigated here, which is relevant for commercial Al-doped glass as used in, e.g., rareearth doped optical amplifiers.

The results in Fig. 5(b) were obtained under the assumption that the independent $\mathrm{Al}$ ions still had the same mean energy as those in the $\alpha$-quartz $\mathrm{Al}_{2} V_{O}$ structure. However, one could argue that ions moving freely would preferably occupy positions in the lattice where they could form an extra Al-O bond. Taking the energy gain from the formation of a fourth $\mathrm{Al}-\mathrm{O}$ bond to be $0.1 \mathrm{eV}$ per $\mathrm{Al}$ atom as in the cristobalite host the curves of Fig. 5(b) are not changed very much. Taking the gain to be $0.44 \mathrm{eV}$ as estimated from the comparison of $\alpha$-quartz and $\alpha$-cristobalite results one obtains the curves depicted in Fig. 5(c). The $\mathrm{Al}_{4}\left[V_{O}\right]_{2}$ states are still dominant at the highest concentrations, but for doping in the $0.1-1 \%$ range a mixture of states is present. As discussed above, the $0.44-\mathrm{eV}$ energy gain is probably an overestimate due to the difference in size of the supercells used. On the other hand, in amorphous silica one could speculate that the energy gain would be site dependent and that certain favorable sites would be preferentially occupied, thus increasing the importance of the isolated Al state. However, obtaining a reliable estimate of such a site energy dis-
TABLE III. Hyperfine parameters (in $\mathrm{cm}^{-1}$ ) for the paramagnetic states $\mathrm{Al} V_{O}$ and $\left[\mathrm{Al}_{2} V_{O}\right]^{-}$. Only the isotropic coupling, $A_{\text {iso }}$, and the largest component of the anisotropic matrix, $A_{a n}$, are given. Atom 1 is at the short-bonded site which is always three coordinated, while atom 2 is at the long-bonded site and may be three or four coordinated. The $\mathrm{Al}[3]-\mathrm{Al}[4]$ structure is the equilibrium geometry of the neutral $\mathrm{Al}_{2} V_{O}$ state. See text for further details.

\begin{tabular}{lcccc}
\hline \hline System & \multicolumn{2}{c}{ Atom 1 } & \multicolumn{2}{c}{ Atom 2 } \\
\hline & $A_{\text {iso }}$ & $A_{\text {an }}$ & $A_{\text {iso }}$ & $A_{\text {an }}$ \\
$\mathrm{Al}[3]-\mathrm{Si}[3]$ & 0.0001 & 0.0000 & -0.0418 & -0.0047 \\
$\mathrm{Al}[3]-\mathrm{Si}[4]$ & 0.0056 & 0.0002 & -0.0085 & -0.0002 \\
$\mathrm{Si}[3]-\mathrm{Al}[4]$ & -0.0446 & -0.0046 & -0.0001 & 0.0000 \\
$\mathrm{Al}[3]-\mathrm{Al}[3]$ & 0.0141 & 0.0021 & 0.0134 & 0.0020 \\
$\mathrm{Al}[3]-\mathrm{Al}[4]$ & 0.0315 & 0.0029 & 0.0008 & 0.0000 \\
\hline \hline
\end{tabular}

tribution is an extremely demanding computational problem beyond the scope of the present work.

\section{Hyperfine parameters}

Hyperfine parameters have been calculated for the various $\mathrm{Al} V_{O}$ states as well as for the $\left[\mathrm{Al}_{2} V_{O}\right]^{-}$state. For the latter, calculations were performed in two geometries: The equilibrium geometry of the neutral state in which the unpaired spin is found to be essentially localized on the $\mathrm{Al}[3]$ ion and the equilibrium geometry of the negative charge state, in which the unpaired electron forms a covalent bond between the two $\mathrm{Al}$ ions. The theoretical results are summarized in Table III. All hyperfine tensors are found to have approximate axial symmetry (to an accuracy of $\sim 1 \%$ ), except for that of the rebonded $\mathrm{Al}$ ion in the unrelaxed $\left[\mathrm{Al}_{2} V_{O}\right]^{-}$configuration, which is very small. This means that two components of the anisotropic part are identical, while the third is twice as large and has the opposite sign, so that the anisotropic tensor is traceless. In the table, only the largest component of the anisotropic term is therefore given.

Experimentally, most EPR studies of crystalline $\alpha$-quartz have found signals corresponding to $\mathrm{Al}[4]$ ions, either in the neutral isolated state or in the presence of a positive alkali ion such as $\mathrm{H}, \mathrm{Li}, \mathrm{Na}$, etc. The EPR signals are only seen upon irradiation of the samples. It is believed that the $\mathrm{Al}$ ions in the unirradiated material are present in substitutional positions in the quartz lattice, with an extra electron filling the hole in the valence band arising from the reduced valence of the $\mathrm{Al}$ ion compared to $\mathrm{Si}$. An alkali ion is present nearby to compensate the excess charge. In natural quartz containing only trace amounts of Al there is often sufficient alkali impurities present to compensate all $\mathrm{Al}$ ions. In silica glass doped primarily with $\mathrm{Al}$ this is obviously not the case, and these states are therefore less interesting in this context. Brower measured another series of hyperfine signals in silica glass which he interpreted as coming from $\mathrm{Al}[3]$ ions with a trapped electron, either isolated or in the presence of an alkali ion. ${ }^{13}$ The signal attributed to isolated $\mathrm{Al}[3]$ was found to have an isotropic hyperfine parameter of $0.0331 \mathrm{~cm}^{-1}$ and an anisotropic coupling of $0.0030 \mathrm{~cm}^{-1}$ (largest value of anisotropic matrix) in very good agreement with the theoretical 
result for the unrelaxed $\left[\mathrm{Al}_{2} V_{O}\right]^{-}$state in which the unpaired spin is localized on a single $\mathrm{Al}[3]$ ion. On the other hand, no signal corresponding to the relaxed $\left[\mathrm{Al}_{2} V_{O}\right]^{-}$geometry was seen. The signal from $\mathrm{Al}[3]$ was not observed in crystalline $\alpha$-quartz and was also absent in glasses containing high concentrations of alkali ions. The concentration of $\mathrm{Al}$ ions in the $\mathrm{Al}[3]$-containing samples was $10-50 \mathrm{ppm}$ by weight. This is below the concentration regime where the $\mathrm{Al}_{4}\left[V_{O}\right]_{2}$ states would be expected to become important if the $\mathrm{Al}$ ions are uncorrelated, provided that the thermodynamical considerations of the previous section are applicable. On the other hand, if the Al ions are paired (as is necessarily the case in crystalline quartz, where they share an $\mathrm{O}$ vacancy) the $\mathrm{Al}_{4}\left[V_{O}\right]_{2}$ state is expected to become dominant at much lower concentrations. The fact that $\mathrm{Al}[3]$ ions are seen in glass but not in quartz can thus be taken as an indication that $\mathrm{Al}$ ions are indeed uncorrelated in the amorphous state at low concentrations. The absence of an EPR signal corresponding to the relaxed $\left[\mathrm{Al}_{2} V_{O}\right]^{-}$configuration is another strong argument for this hypothesis.

Concerning the various $\mathrm{Al} V_{O}$ states it is interesting to notice that none of them give rise to a strong ${ }^{27} \mathrm{Al}$ hyperfine signal. Therefore the signal measured by Brower has no contribution from such structures. In the state with a rebonded $\mathrm{Si}$ atom all hyperfine parameters are quite small, indicating that the unpaired spin is largely located in the interstitial region. In the other states, the spin is almost completely localized on the Si cation. The hyperfine parameters found are slightly larger than the experimental results for the $E_{1}^{\prime}$ center in pure silica, but in good agreement with the theoretical results of Boero et al. ${ }^{30}$ suggesting that the difference is related to the theoretical approximations rather than the presence of Al. Brower observed that the magnitude of the Si $E_{1}^{\prime}$ signal appeared to follow the $\mathrm{Al}$ concentration, and speculated that this might be related to an $\mathrm{Al} V_{O}$ state. ${ }^{13}$ The present calculations show that this is a valid hypothesis insofar as the hyperfine $\mathrm{Al} V_{O}$ signal should be similar to the ordinary $\mathrm{Si}-\mathrm{Si}$ $E_{1}^{\prime}$ signal.

\section{Core level shifts}

Various forms of core-level spectroscopies have been found to provide useful information about the chemical states of impurities in silica. In crystalline samples, x-ray fluorescence (XFS) from the $K_{\alpha}$ emission provides a clear distinction between different coordination states of cations such as $\mathrm{Al}, \mathrm{Si}$, and $\mathrm{Ge}$. It has recently been shown that this quantity is predicted with very good accuracy by DFT calculations. ${ }^{11}$ The calculated chemical shifts, referenced to metallic $\mathrm{Al}$, are reported in Table IV for the $\mathrm{Al}$ ions in the $\mathrm{Al}_{2} V_{O}, \mathrm{Al}_{4}\left[V_{O}\right]_{2}^{(2)}$, and $\mathrm{Al}_{4}\left[V_{O}\right]_{2}^{(3)}$ geometries. Generally, the shifts have been found to follow the coordination number of the $\mathrm{Al}$ ion in question quite closely, so that the interstitial $\mathrm{Al}[4]$ ion in the $\mathrm{Al}_{4}\left[V_{O}\right]_{2}^{(2)}$ geometry has a shift similar to the substitutional ions. The shifts are, as is usually the case, found to increase with increasing coordination number. This can be understood as an effect of decreasing charge density at the $\mathrm{Al}$ cation: The $2 p$ core hole provides a less attractive electrostatic potential for the valence electrons than the more
TABLE IV. Calculated chemical shifts of the $\mathrm{Al} K_{\alpha}$ radiation line in different impurity states and in crystalline $\mathrm{Al}_{2} \mathrm{O}_{3}$.

\begin{tabular}{lccc}
\hline \hline System & Atom & Coordination & $K \alpha$ chem. shift $(\mathrm{eV})$ \\
\hline $\mathrm{Al}_{2} V_{O}$ & $\mathrm{~A} 11$ & 3 & 0.257 \\
& $\mathrm{~A} 12$ & 4 & 0.339 \\
$\mathrm{Al}_{4}\left[V_{O}\right]_{2}^{(2)}$ & $\mathrm{A} 11$ & 4 & 0.340 \\
& $\mathrm{~A} 12$ & 4 & 0.320 \\
& $\mathrm{~A} 13$ & 4 & 0.336 \\
& $\mathrm{~A} 14$ & 4 & 0.326 \\
$\mathrm{Al}_{4}\left[V_{O}\right]_{2}^{(3)}$ & $\mathrm{A} 11$ & 5 & 0.472 \\
& $\mathrm{~A} 12$ & 4 & 0.345 \\
& $\mathrm{Al} 3$ & 4 & 0.325 \\
& $\mathrm{~A} 14$ & 4 & 0.328 \\
$\alpha-\mathrm{Al}_{2} \mathrm{O}_{3}$ & & 6 & 0.434 \\
\hline \hline
\end{tabular}

compact $1 s$ hole, meaning that the attraction between core hole and valence electrons will be stronger for the $1 s$ hole, i.e., the initial state energy of the $K_{\alpha}$ transition is reduced more than the final-state energy by the interaction with the valence electrons. Therefore a smaller valence charge density on $\mathrm{Al}$ will lead to larger transition energies, i.e., a larger chemical shift. It is noteworthy that the shift of the $\mathrm{Al}[5]$ ion in $\mathrm{Al}_{4}\left[V_{O}\right]_{2}^{(3)}$ is larger than the shift of $\mathrm{Al}[6]$ in crystalline $\mathrm{Al}_{2} \mathrm{O}_{3}$ (also given in Table IV). This shows that the $\mathrm{Al}$ ion becomes more positive in a silica environnment, which is a reasonable finding given that the $s p$ levels of $\mathrm{Al}$ are higher in energy than those of $\mathrm{Si}$. Another interesting result is that the chemical shift of the rebonded $\mathrm{Al}$ ion in the $\mathrm{Al}_{2} V_{O}$ state is close to that of the substitutional ions in the $\mathrm{Al}_{4}\left[V_{O}\right]_{2}$ states, indicating that the charge transfer away from the $\mathrm{Al}$ core region through the stretched bond is as effective as that which takes place through the bonds of the substitutional ions. The results presented so far show that the chemical shifts of the $\mathrm{Al} K_{\alpha}$ line can provide a measure of the distribution of $\mathrm{Al}$ between different coordination states, but that it cannot distinguish ions of the same coordination in different structures (such as $\mathrm{Al}[4]$ in $\mathrm{Al}_{2} V_{O}$ and $\mathrm{Al}_{4}\left[V_{O}\right]_{2}$ ). The situation is different if one considers the shifts of the $1 s$ or $2 p$ states individually. These shifts can be measured by $\mathrm{x}$-ray photoemission spectroscopy (XPS). In Table V the relative

TABLE V. Calculated chemical shifts of the Al $2 p$ binding energy in the $\mathrm{Al}_{4}\left[V_{O}\right]_{2}^{(2)}$ and $\mathrm{Al}_{4}\left[V_{O}\right]_{2}^{(3)}$ structures.

\begin{tabular}{lcccc}
\hline \hline System & Atom & Coordination & $\left\langle d_{A l-O}\right\rangle(\AA)$ & $E_{2 p}(\mathrm{eV})$ \\
\hline $\mathrm{Al}_{4}\left[V_{O}\right]_{2}^{(2)}$ & $\mathrm{A} 11$ & 4 & 1.797 & -2.07 \\
& $\mathrm{~A} 12$ & 4 & 1.774 & -0.52 \\
& $\mathrm{Al} 3$ & 4 & 1.749 & 0.50 \\
& $\mathrm{~A} 14$ & 4 & 1.759 & 0.02 \\
$\mathrm{Al}_{4}\left[V_{O}\right]_{2}^{(3)}$ & $\mathrm{A} 11$ & 5 & 1.907 & -1.67 \\
& $\mathrm{Al} 2$ & 4 & 1.762 & -0.19 \\
& $\mathrm{Al} 3$ & 4 & 1.766 & -0.34 \\
& $\mathrm{Al} 4$ & 4 & 1.756 & 0.53 \\
\hline \hline
\end{tabular}


shifts of the $\mathrm{Al} 2 p$ levels in the $\mathrm{Al}_{4}\left[V_{O}\right]_{2}^{(2)}$ and $\mathrm{Al}_{4}\left[V_{O}\right]_{2}^{(3)}$ states are reported. Within each structure, the energies are measured relative to the mean level position of the substitutional $\mathrm{Al}$ ions (labeled $\mathrm{Al}[2]-\mathrm{Al}[4]$ in Table $\mathrm{V}$ ). The level positions of these ions in both case disperse over $\sim 1 \mathrm{eV}$ while the level position of the interstitial $\mathrm{Al}$ is $1.3-1.5 \mathrm{eV}$ below the lowest substitutional $2 p$ level. For the $\mathrm{Al}[4]$ ions the shifts correlate with the average $\mathrm{Al}-\mathrm{O}$ bond lengths also given in Table $\mathrm{V}$. These are again connected with the number of $\mathrm{O}[3]$ neighbor atoms since the bonds to these are longer. Thus the crucial difference between substitutional and interstitial $\mathrm{Al}$ atoms is the fact that the interstitials are only bonded to $\mathrm{O}[3]$ atoms, whereas the substitutionals typically have one or two $\mathrm{O}[3]$ neighbors.

The difference between XPS and XFS in distinguishing various $\mathrm{Al}$ species can be understood in the following way: When a core hole is introduced at an $\mathrm{Al}$ atom the valence of this atom is effectively changed by one, so extra charge is attracted from its $\mathrm{O}$ neighbors. The XPS shifts represent the difference in energy between core holes residing on different atoms and the energy gained by attracting extra charge from the neighbors depends on the nature of these (e.g., whether they are $\mathrm{O}[2]$ or $\mathrm{O}[3]$ species). However, these site differences largely cancel out when considering XFS shifts, which are differences between $1 s$ and $2 p$ core hole energies. The XFS shifts are roughly determined by the amount of charge present in the core region of the $\mathrm{Al}$ atom with the core hole, and this quantity appears to follow the coordination state of the atom quite closely. On the other hand, the energy gained by attracting the charge is higher if $\mathrm{O}[2]$ neighbors are present, which appears reasonable since the total charge on the $\mathrm{O}[3]$ species is lower as will be discussed further below.

Chemical shifts of the $\mathrm{O} 1 s$ levels have been calculated in the $\mathrm{Al}_{4}\left[V_{O}\right]_{2}^{(2)}$ and $\mathrm{Al}_{2} V_{O}$ structures for $\mathrm{O}$ atoms in various coordination states. The $1 s$ level position depends on the coordination number and nearest-neighbor species of the $\mathrm{O}$ atoms. The electronic charge on the $\mathrm{O}$ atom provides an attractive potential for the final-state $1 s$ hole, so electron transfer to $\mathrm{O}$ will raise the $1 \mathrm{~s}$ level position. The electronic charge on $\mathrm{O}$ is increased if $\mathrm{Si}$ neighbors are substituted by $\mathrm{Al}$, since the $\mathrm{Al}$ valence orbitals are higher in energy than the $\mathrm{Si}$ ones, thus increasing the ionicity of the bond to O. On the other hand, an $\mathrm{O}[3]$ atom will carry a smaller electronic charge than an $\mathrm{O}[2]$, since a nonbonding $\mathrm{O} 2 p$ electron is more localized on $\mathrm{O}$ than an electron bonding to $\mathrm{Si}$ or $\mathrm{Al}$. Therefore $\mathrm{O} 1 s$ core-level spectroscopy can in principle give information on the number of $\mathrm{O}[3]$ atoms, and also on the degree of $\mathrm{Al}$ correlation (by distinguishing $\mathrm{O}$ atoms bonded to more than one $\mathrm{Al}$ ion). In Table VI, the shifts of the $1 \mathrm{~s}$ levels relative to that of a reference $O$ atom in the same structure but far from the $\mathrm{Al}$ impurities are listed. Consider first the results for the $\mathrm{Al}_{2} V_{O}$ geometry: In accordance with the above reasoning the $\mathrm{O}[2]$ atoms bonded to $\mathrm{Al}$ have their $1 s$ levels shifted upwards. The $\mathrm{O}[3]$ atom has a negative shift of the $1 \mathrm{~s}$ level, but comparison to the similar atom (neighbored by two $\mathrm{Si}$ and one $\mathrm{Al}$ ) in the $\mathrm{Al}_{4}\left[V_{O}\right]_{2}^{(2)}$ structure shows that the electron transfer to the core region of the $\mathrm{O}[3]$ atom becomes less efficient as the $\mathrm{Al}[4]-\mathrm{O}[3]$ bond is
TABLE VI. Calculated chemical shifts of the O $1 s$ level for some Al-bonded $\mathrm{O}$ atoms relative to a reference $\mathrm{O}$ in the same structure more than $5 \AA$ from the $\mathrm{Al}$ impurities.

\begin{tabular}{lccc}
\hline \hline System & Atom & Neighbors & Chem. shift $(\mathrm{eV})$ \\
\hline $\mathrm{Al}_{2} V_{O}$ & 1 & $\mathrm{Si}, \mathrm{Al}[3]$ & 0.60 \\
& 2 & $\mathrm{Si}, \mathrm{Al}[4]$ & 0.96 \\
& 3 & $\mathrm{Si}, \mathrm{Al}[4]$ & 0.87 \\
& 4 & $2 \mathrm{Si}, \mathrm{Al}[4]$ & -1.26 \\
$\mathrm{Al}_{4}\left[V_{O}\right]_{2}^{(2)}$ & & & \\
& 1 & $3 \mathrm{Al}$ & 0.15 \\
& 2 & $\mathrm{Si}, 2 \mathrm{Al}$ & -1.14 \\
& 3 & $\mathrm{Si}, 2 \mathrm{Al}$ & -1.39 \\
& 4 & $2 \mathrm{Si}, \mathrm{Al}$ & -2.04 \\
& 5 & $\mathrm{Si}, \mathrm{Al}$ & 0.80 \\
& 6 & $\mathrm{Si}, \mathrm{Al}$ & 0.90 \\
& 7 & $\mathrm{Si}, \mathrm{Al}$ & 0.92 \\
& 8 & $\mathrm{Si}, \mathrm{Al}$ & 1.40 \\
\hline \hline
\end{tabular}

stretched. This is in contrast to the result for the Al x-ray fluorescence data which indicated that the charge transfer away from the core region of the $\mathrm{Al}[4]$ atom is essentially the same in the two cases, implying that the stretched bond leaves more charge in the interstitial region between the nuclei.

The results obtained in the $\mathrm{Al}_{4}\left[V_{O}\right]_{2}^{(2)}$ structure are also consistent with the simple arguments outlined above. The largest negative level shift is seen for the $\mathrm{O}[3]$ atom having only one $\mathrm{Al}$ neighbor. As the number of $\mathrm{Al}$ neighbors is raised, the chemical shift becomes less negative, and the $1 \mathrm{~s}$ level of an $\mathrm{O}$ atom bonded to three $\mathrm{Al}$ atoms is close to that of the reference $\mathrm{O}$ atom far from the $\mathrm{Al}$ impurities. $\mathrm{O}[2]$ atoms with one $\mathrm{Al}$ neighbor have positive chemical shifts, as expected. Remarkably, one of these (atom 8) has a distinctly larger shift than the other three. The difference is most likely related to the fact that atom 8 has another $\mathrm{Si}-\mathrm{Al}$ bonded $\mathrm{O}$ atom in its second neighbor shell, which is not the case for atoms 1 and 2. The presence of the nearby Al-O bond apparently pushes more negative charge onto atom 8 , showing that the effect of an $\mathrm{Al}$ impurity on $\mathrm{O} 1 s$ level shifts goes beyond the nearest-neighbor shell.

In summary, O $1 s$ core-level shifts only provide a clear distinction between different chemical states of $\mathrm{O}$ atoms if an energy resolution better than $\sim 1 \mathrm{eV}$ can be achieved. Furthermore, for samples with low $\mathrm{Al}$ content, the signal from the Al-related $\mathrm{O}$ species will only be a small feature on the wings of the main Si-O-Si signal and may be difficult to detect.

\section{E. Electric-field gradients}

The electric-field gradient (EFG) at a particular nucleus is a traceless tensor given by

$$
V_{i j}=\frac{\partial^{2} V_{e}}{\partial x_{i} \partial x_{j}},
$$


where $V_{e}$ is the electrostatic potential and the partial derivative is evaluated at the position of the nucleus in question. The tensor is conveniently expressed by two parameters, $V_{z z}$ and $\eta$ where $V_{z z}$ is the principal component of largest magnitude and

$$
\eta=\frac{\left|V_{x x}-V_{y y}\right|}{\left|V_{z z}\right|}, \quad\left|V_{z z}\right| \geqslant\left|V_{x x}\right| \geqslant\left|V_{y y}\right|
$$

The coupling of the electric-field gradient to the quadrupolar moment of a nucleus with nuclear spin quantum number $I$ $>\frac{1}{2}$ can be measured in Mössbauer or NMR spectroscopy. The sign of $V_{z z}$ is not experimentally accessible.

Theoretically, evaluation of the EFG tensor requires knowledge of the electrostatic potential at the nucleus in question, which in turn can be derived from the electronic density. Only the $l=2$ component of $V_{e}$ (in an angularmomentum expansion centered on the nucleus) contributes. In the present formalism, the electronic density in the core region can be reconstructed as explained in Sec. II B, but it is important to notice that the EFG is a quantity which can be quite sensitive to the details of the calculation, and that several approximations are made in the present approach: First, the deformation (spherical as well as nonspherical) of the core states is neglected. Second, the valence basis orbitals in the core region are obtained in a free-atom calculation. Third, Vanderbilt's ultrasoft US-PP method, as well as Blöchl's PAW construction, ${ }^{41}$ relies on a certain completeness assumption which is only approximately (although often with good accuracy) fulfilled. For these reasons, it is important to estimate the accuracy of the method by benchmarking it against other calculations using more accurate schemes.

The $\mathrm{Al}_{2} \mathrm{SiO}_{5}$ polymorphs silimanite and andalusite have recently been studied theoretically by several authors in order to extract $\mathrm{EFG}$ parameters for $\mathrm{Al}$ and $\mathrm{O}$ nuclei in various coordination states. ${ }^{47,28,27}$ These studies were performed using the highly accurate full potential linear augmented planewave (FLAPW) method within the LDA approximation. The advantages of FLAPW compared to the present method is an explicit treatment of the wave function in the core region and the possibility of including semicore orbitals like the $\mathrm{Al} 2 p$ 's in the valence basis set. The existence of such accurate theoretical calculations as well as experimental data makes these crystals an obvious test case for the US-PP method. In Table VII EFG values for silimanite and andalusite obtained using US-PP's are compared to FLAPW results ${ }^{27,28}$ as well as experimental values. ${ }^{48,47}$ To investigate the importance of the atomic basis orbitals used in the US-PP construction, calculations were performed using two different $\mathrm{O}$ pseudopotentials denoted PP1 and PP2 in Table VII: PP1 is the one used for the structural relaxations, and has two atomic orbitals in each of the $s$ and $p$ channels. PP2 has an extra orbital in the $p$ channel. It can be seen that the EFG values obtained with different FLAPW codes and parameter choices are generally in good agreement with each other although in a few cases deviations of $5-10 \%$ occur. The US-PP results for $\left|V_{z z}\right|$ at the Al nuclei are consistently smaller than those obtained using FLAPW, in one case by almost $40 \%$, and are $20-50 \%$ smaller than the experimental values. On the other
TABLE VII. EFG parameters for the $\mathrm{Al}_{2} \mathrm{SiO}_{5}$ polymorphs silimanite and andalusite, reported in atomic units. The sign of $V_{z z}$ has been omitted since it cannot be determined experimentally and was not given in Ref. 27. The signs reported in Ref. 28 were consistent with those obtained in the present work.

\begin{tabular}{|c|c|c|c|c|c|c|}
\hline Atom & & (Ref. 28) & (Ref. 27) & PP1 & PP2 & Expt. \\
\hline \multicolumn{7}{|c|}{ Silimanite } \\
\hline \multirow[t]{2}{*}{$\operatorname{Al}(1)$} & $\left|V_{z z}\right|$ & 0.239 & 0.238 & 0.232 & 0.231 & 0.271 \\
\hline & $\eta$ & 0.49 & & 0.48 & 0.47 & 0.46 \\
\hline \multirow[t]{2}{*}{$\mathrm{Al}(2)$} & $\left|V_{z z}\right|$ & 0.187 & 0.189 & 0.137 & 0.137 & 0.206 \\
\hline & $\eta$ & 0.51 & & 0.74 & 0.78 & 0.53 \\
\hline \multirow[t]{2}{*}{$\mathrm{O}(1)$} & $\left|V_{z z}\right|$ & 0.596 & 0.619 & 0.683 & 0.647 & \\
\hline & $\eta$ & 0.67 & & 0.67 & 0.68 & \\
\hline \multirow[t]{2}{*}{$\mathrm{O}(2)$} & $\left|V_{z z}\right|$ & 0.525 & 0.537 & 0.622 & 0.583 & \\
\hline & $\eta$ & 0.01 & & 0.05 & 0.07 & \\
\hline \multirow[t]{2}{*}{$\mathrm{O}(3)$} & $\left|V_{z z}\right|$ & 0.654 & 0.704 & 0.778 & 0.752 & \\
\hline & $\eta$ & 0.08 & & 0.07 & 0.08 & \\
\hline \multirow[t]{2}{*}{$\mathrm{O}(4)$} & $\left|V_{z z}\right|$ & 0.669 & 0.733 & 0.827 & 0.775 & \\
\hline & $\eta$ & 0.52 & & 0.47 & 0.49 & \\
\hline \multicolumn{7}{|c|}{ Andalusite } \\
\hline \multirow[t]{2}{*}{$\mathrm{Al}(1)$} & $\left|V_{z z}\right|$ & 0.423 & 0.426 & 0.367 & 0.365 & 0.464 \\
\hline & $\eta$ & 0.08 & & 0.14 & 0.14 & 0.10 \\
\hline \multirow[t]{2}{*}{$\mathrm{Al}(2)$} & $\left|V_{z z}\right|$ & 0.162 & 0.159 & 0.140 & 0.139 & 0.177 \\
\hline & $\eta$ & 0.73 & & 0.93 & 0.95 & 0.67 \\
\hline \multirow[t]{2}{*}{$\mathrm{O}(1)$} & $\left|V_{z z}\right|$ & 0.473 & 0.489 & 0.560 & 0.535 & \\
\hline & $\eta$ & 0.18 & & 0.15 & 0.14 & \\
\hline \multirow[t]{2}{*}{$\mathrm{O}(2)$} & $\left|V_{z z}\right|$ & 0.602 & 0.615 & 0.691 & 0.664 & \\
\hline & $\eta$ & 0.83 & & 0.79 & 0.79 & \\
\hline \multirow[t]{2}{*}{$\mathrm{O}(3)$} & $\left|V_{z z}\right|$ & 0.409 & 0.420 & 0.478 & 0.463 & \\
\hline & $\eta$ & 0.85 & & 0.88 & 0.87 & \\
\hline \multirow[t]{2}{*}{$\mathrm{O}(4)$} & $\left|V_{z z}\right|$ & 0.687 & 0.705 & 0.638 & 0.594 & \\
\hline & $\eta$ & 0.51 & & 0.38 & 0.38 & \\
\hline
\end{tabular}

hand, for all the $\mathrm{O}$ nuclei except one, $\left|V_{z z}\right|$ is overestimated compared to FLAPW (no experimental data exist here). However, the differences are somewhat smaller, around 10$15 \%$. Most likely, the disagreement is caused by the frozen nature of the orbitals used in the PAW-like reconstruction of the charge distribution in the core region. When the $\mathrm{Al}$ ions are depleted of electronic charge by oxidation, the electronic orbitals must be expected to contract somewhat, increasing the asymmetric charge component close to the nucleus and thereby the EFG. The charge depleted from Al is transferred to the $\mathrm{O}$ ions, whose orbitals would therefore expand leading, by the same reasoning, to a reduction of the EFG. The atomiclike basis orbitals used in the US-PP construction are not able to respond to this charge redistribution, whereas the effect is included in the LAPW approximation. In the case of $\mathrm{Al}$, an additional shortcoming of the US-PP method is that the deformation of the $\mathrm{Al} 2 p$ states is not accounted for. This explains why the difference between LAPW and the US-PP method is larger for $\mathrm{Al}$ than for $\mathrm{O}$. It can be seen from Table VII that the PP2 results for $\mathrm{O}$ are generally closer to the LAPW data, confirming that the limited variational degrees of freedom in the radial charge distribution is an important 
TABLE VIII. EFG parameters for the $\mathrm{Al}$ ions in the $\mathrm{Al}_{2} V_{O}$, $\mathrm{Al}_{4}\left[V_{O}\right]_{2}^{(2)}$, and $\mathrm{Al}_{4}\left[V_{O}\right]_{2}^{(3)}$ structures. The numbering is as in Table IV.

\begin{tabular}{|c|c|c|c|}
\hline Atom & $Z$ & $\left|V_{z z}\right|$ (a.u.) & $\eta$ \\
\hline \multicolumn{4}{|c|}{$\mathrm{Al}_{2} V_{O}$} \\
\hline Al1 & 3 & 0.88 & 0.13 \\
\hline $\mathrm{A} 12$ & 4 & 0.53 & 0.20 \\
\hline \multicolumn{4}{|c|}{$\mathrm{Al}_{4}\left[V_{O}\right]_{2}^{(2)}$} \\
\hline Al1 & 4 & 0.36 & 0.98 \\
\hline $\mathrm{A} 12$ & 4 & 0.48 & 0.77 \\
\hline Al3 & 4 & 0.25 & 0.31 \\
\hline Al4 & 4 & 0.45 & 0.29 \\
\hline \multicolumn{4}{|c|}{$\mathrm{Al}_{4}\left[V_{O}\right]_{2}^{(3)}$} \\
\hline Al1 & 5 & 0.25 & 0.37 \\
\hline A12 & 4 & 0.38 & 0.51 \\
\hline $\mathrm{A} 13$ & 4 & 0.46 & 0.71 \\
\hline Al4 & 4 & 0.32 & 0.28 \\
\hline
\end{tabular}

source of error in the present calculations. For this reason, the PP2 potential was used for the calculation of EFG's in the $\mathrm{SiO}_{2}: \mathrm{Al}_{2} \mathrm{O}_{3}$ structures.

The calculated EFG parameters for the $\mathrm{Al}$ ions in the $\mathrm{Al}_{2} V_{O}$ and the two $\mathrm{Al}_{4}\left[V_{O}\right]_{2}$ configurations of lowest energy are given in Table VIII. The $\mathrm{Al}[3]$ ion is found to have the highest $\left|V_{z z}\right|$ value and the $\mathrm{Al}[5]$ ion the lowest. However, the $\mathrm{Al}[4]$ ions show a large variation in the EFG strength, which can therefore not be taken as a measure of the coordination state alone. It is interesting to compare the results for doped quartz with those found for the $\mathrm{Al}_{2} \mathrm{SiO}_{5}$ crystals. In both andalusite and silimanite the ions denoted $\mathrm{Al}(1)$ are $\mathrm{Al}[6]$, while $\mathrm{Al}(2)$ are $\mathrm{Al}[5]$ (andalusite) or $\mathrm{Al}[4]$ (silimanite). Thus in this case the high-coordinated $\mathrm{Al}$ ions have the largest EFG's. The reason, at least for the case of silimanite, is likely to be the larger dispersion of Al-O bond lengths for the $\mathrm{Al}[6]$ species. Such a trend was not apparent in the $\mathrm{Al}_{4}\left[V_{O}\right]_{2}$ structures. Therefore a shift of the Al ions towards higher coordination states in a glass should be accompanied by a decrease in EFG values.

EFG values for all $\mathrm{O}$ ions bonded to $\mathrm{Al}$ in the $\mathrm{Al}_{4}\left[V_{O}\right]_{2}^{(2)}$ structure as well as a reference ion located far from the $\mathrm{Al}$ impurities are given in Table IX. The distribution of $\left|V_{z z}\right|$ values is more narrow here, and a clear distinction can be made between $\mathrm{O}$ ions with and without bonds to Al. On the other hand, considering the Al-bonded ions no clear distinction can be made between $\mathrm{O}[2]$ and $\mathrm{O}[3]$ species on the basis of the $\left|V_{z z}\right|$ values alone. However, as might be expected $\mathrm{O}[2]$ tends more towards axial symmetry $(\eta=0)$ than $\mathrm{O}[3]$. For the $\mathrm{O}[3]$ ions a trend towards higher EFG values with decreasing number of $\mathrm{Al}$ neighbors is apparent. These observations are consistent with the results obtained by Tossell and Cohen $^{27}$ in calculations using the Becke-Lee-Yang-Parr (LYP) functional on small clusters with a Gaussian basis set. The $\left|V_{z z}\right|$ values reported by these authors for $\mathrm{O}[3]$ species with various kinds of neighbors are close to or slightly higher than the present results, whereas their results for $\mathrm{O}[2]$ species with either two $\mathrm{Si}$ or one $\mathrm{Si}$ and one $\mathrm{Al}$ neighbor are
TABLE IX. EFG parameters for some of the $\mathrm{O}$ atoms bonded to $\mathrm{Al}$ in the $\mathrm{Al}_{4}\left[V_{O}\right]_{2}^{(2)}$ structure. The reference atom is more than $5 \AA$ away from any of the $\mathrm{Al}$ impurities.

\begin{tabular}{lccc}
\hline \hline Atom & Neighbors & $\left|V_{z z}\right|$ (a.u.) & $\eta$ \\
\hline 1 & $3 \mathrm{Al}$ & 0.54 & 0.35 \\
2 & $\mathrm{Si}, 2 \mathrm{Al}$ & 0.74 & 0.73 \\
3 & $\mathrm{Si}, 2 \mathrm{Al}$ & 0.65 & 0.81 \\
4 & $2 \mathrm{Si}, \mathrm{Al}$ & 0.89 & 0.63 \\
5 & $\mathrm{Si}, \mathrm{Al}$ & 0.72 & 0.26 \\
6 & $\mathrm{Si}, \mathrm{Al}$ & 0.70 & 0.56 \\
7 & $\mathrm{Si}, \mathrm{Al}$ & 0.74 & 0.28 \\
8 & $\mathrm{Si}, \mathrm{Al}$ & 0.71 & 0.26 \\
Ref. & $2 \mathrm{Si}$ & 1.02 & 0.17 \\
\hline \hline
\end{tabular}

lower (by 10-20\%) than the present findings. In view of the results for silimanite and andalusite, which showed that the US-PP method tends to overestimate O EFG values by $\sim 10 \%$, this indicates that the cluster models provide a good description of the $\mathrm{O}[2]$ species but overestimates the $\left|V_{z z}\right|$ values of $\mathrm{O}[3]$ atoms.

Experimentally, Al EFG parameters have only been studied in glasses with rather high $\mathrm{Al}_{2} \mathrm{O}_{3}$ concentrations (10 mole $\%$ or more) due to the limited sensitivity of NMR. The results recently reported by Schaller and Stebbins ${ }^{17}$ for Laand Y-codoped aluminosilicates correspond to $\left|V_{z z}\right|$ values around $0.10-0.15$ a.u. Similar values were obtained by McManus et al. for glass approximately of Mullite composition $\left(3 \mathrm{Al}_{2} \mathrm{O}_{3}: 2 \mathrm{SiO}_{2}\right) .{ }^{19}$ These values are considerably lower than the ones obtained here, which is remarkable given that the findings for the $\mathrm{Al}_{2} \mathrm{SiO}_{5}$ polymorphs suggest that the $\mathrm{Al} E F G$ values are somewhat underestimated by the US-PP method. This shows that $\mathrm{Al}$ in these materials sits in more symmetric local environments than the $\mathrm{Al}$ ions in the impurity structures studied here. Whether this is due to the greater flexibility of amorphous silica networks compared to the quartz supercells used here, or to the formation of more extended Si-Al-O structures at high $\mathrm{Al}_{2} \mathrm{O}_{3}$ concentrations, remains an open question. However, the comparison of structural data with the EXAFS results of $\mathrm{Sen}^{14}$ discussed in Sec. III A suggests that the present approach does indeed overestimate the Al-O bond length dispersion slightly (Sen's experiments were conducted on glasses with an $\mathrm{Al}_{2} \mathrm{O}_{3}$ concentration below 1 mole \%), and can therefore also be expected to overestimate the magnitude of the EFG tensors.

NMR spectroscopy on $\mathrm{O}$ ions is a difficult task due to the low abundance of the NMR-active ${ }^{17} \mathrm{O}$ isotope. Results for ${ }^{17} \mathrm{O}$-enriched samples of sodium aluminosilicate glasses have been reported by several authors. ${ }^{49-52}$ As an example, Dirken et al. ${ }^{49}$ attributed $\left|V_{z z}\right|$ values of 0.87 and 0.60 a.u. in a $\mathrm{NaAlSi}_{3} \mathrm{O}_{8}$ glass to $\mathrm{Si}-\mathrm{O}-\mathrm{Si}$ and $\mathrm{Al}-\mathrm{O}-\mathrm{Si}$ linkages, respectively, in reasonable agreement with the results found here considering the tendency of the US-PP method to overestimate O EFG's. Interestingly, no evidence was found of Al$\mathrm{O}-\mathrm{Al}$ linkages, which are also absent in all the structures found in the present work. The absence of such links does not necessarily rule out $\mathrm{Al}$ clustering as seen from the present calculations where all $\mathrm{Al}$ ions have at least one $\mathrm{Al}$ in 
the second neighbor shell, although no Al-O-Al links are found (disregarding $\mathrm{O}[3]$ species). Rather it demonstrates that certain $\mathrm{Al}$ structures avoiding $\mathrm{Al}-\mathrm{O}-\mathrm{Al}$ links are preferred.

\section{DISCUSSION}

The structural and energetic results presented in the previous section suggest the following picture of $\mathrm{Al}_{2} \mathrm{O}_{3}$ impurity behavior in silica glass: At low concentrations $\mathrm{Al}$ will be present as isolated or paired $\mathrm{Al}[3]$ or $\mathrm{Al}[4]$ species depending on the local environment. As the $\mathrm{Al}_{2} \mathrm{O}_{3}$ concentration increases formation of $\mathrm{Al}_{4}\left[V_{O}\right]_{2}$ states will gradually be favored. However, the results of Sec. III B show that the total energies obtained here cannot provide a quantitative estimate of the concentration range in which the transition to $\mathrm{Al}_{4}\left[V_{O}\right]_{2}$ states occur. There are at least four difficult points:

(i) There is a large number of possible $\mathrm{Al}_{4}\left[V_{O}\right]_{2}$ structures, even in an ordered host like $\alpha$-quartz. Only a subset of these have been included in the present model.

(ii) It is not clear whether neutral, nonmagnetic $\mathrm{Al}$ impurities can move independently in amorphous silica, or whether they need to pair in order to share an $\mathrm{O}$ vacancy (as they must in a crystalline host). Both hypotheses were investigated in Sec. III B and were found to give quite different results for the impurity state distribution as a function of concentration.

(iii) The structural results for the $\mathrm{Al}_{2} V_{O}$ defect in $\alpha$-quartz and $\alpha$-cristobalite suggest that isolated $\mathrm{Al}$ impurities will have three strong bonds and one which is weaker or wholly absent. However, one could speculate that the greater relaxational freedom in silica glass (and, in particular, in a silica melt) would make the formation of $\mathrm{Al}[4]$ species with four strong bonds easier. If so, it is possible that the formation of $\mathrm{Al}_{4}\left[V_{O}\right]_{2}$ species would not occur at all but the glass would consist of independent $\mathrm{Al}[4]$ ions up to very high $\mathrm{Al}_{2} \mathrm{O}_{3}$ concentrations.

(iv) Finally the assumption of a thermodynamical equilibrium state used in Sec. III B is questionable. It appears reasonable in melt-quenched glasses but may not be appropriate in other cases (e.g., glass manufactured by the sol-gel or plasma-enhanced chemical-vapor deposition (PECVD) methods).

Since the theoretical results does not provide a full understanding of $\mathrm{Al}$ impurity behavior it is important to consider the available experimental information. In the lowconcentration regime, an important series of EPR experiments were carried out by Brower. ${ }^{12,13}$ His assignment of a ${ }^{27} \mathrm{Al}$ hyperfine signal with an isotropic coupling constant of $0.0331 \mathrm{~cm}^{-1}$ to an $\mathrm{Al}[3]$ ion with a trapped electron is confirmed by the results of Sec. III C. There are several interesting aspects of Brower's results: First, he observed the $\mathrm{Al}[3]$ signal in silica manufactured from natural quartz by electrical melting in a vacuum or inert gas, but failed to observe it in similar quartz samples prior to melting. Second, he did not observe a signal corresponding to the one calculated in Sec. III C for a spin evenly distributed over two $\mathrm{Al}$ nuclei. And third, the concentration of paramagnetic $\mathrm{Al}[3]$ impurities was found to be $\sim 3 \times 10^{16} \mathrm{~cm}^{-3}$ after irradiation, and three times higher after $\mathrm{H}$ sweeping. The first and second finding has implications for the question of $\mathrm{Al}$ pairing. In $\alpha$-quartz, the equilibrium geometry of the $\mathrm{Al}_{2} V_{O}$ state had one $\mathrm{Al}[3]$ and one $\mathrm{Al}[4]$ atom with no chemical bonding between them. However, upon electron addition the weak Al-O bond of the $\mathrm{Al}[4]$ atom is broken and an $\mathrm{Al}-\mathrm{Al}$ bond is formed. If the $\mathrm{Al}$ impurities in Brower's samples were present in $\mathrm{Al}_{2} V_{O}$-like pairs one would expect at least some of them to form an $\mathrm{Al}$-Al bonded state upon trapping an electron. Therefore the absence of the corresponding EPR signal is an indication that the $\mathrm{Al}$ ions are, in fact, not paired to each other. This could also explain why neither the $\mathrm{Al}[3]$ signal, nor the signal from the $\left[\mathrm{Al}_{2} V_{O}\right]^{-}$equilibrium geometry was observed in quartz samples. In crystalline quartz, neutral diamagnetic $\mathrm{Al}$ impurities have to be paired in order to share an $\mathrm{O}$ vacancy. The results presented in Fig. 5(a) show that the $\mathrm{Al}_{2} V_{O}$ state in this situation is disfavored for all concentrations of practical interest (the $\mathrm{Al}$ concentration in Brower's samples was $10-50$ ppm by weight). However, if the $\mathrm{Al}$ ions in the $\mathrm{Al}_{2} V_{O}$ state become independent the state is stabilized up to an $\mathrm{Al}_{2} \mathrm{O}_{3}$ concentration range of $\sim 10^{-4}-10^{-3}$ mole $\%$, in agreement with Brower's observations for amorphous silica.

The concentration results reported by Brower are also significant. They put a lower limit of $1-3 \%$ on the fraction of Al ions in the $\mathrm{Al}[3]$ state. This suggests that many of the isolated $\mathrm{Al}$ ions in the glass do not form four strong bonds but rather that a distribution of bond lengths is present, i.e., that the notion of a site energy distribution for isolated $\mathrm{Al}$ ions suggested at the end of Sec. III B is not unreasonable. As long as $\mathrm{Al}_{4}\left[V_{O}\right]_{2}$ states do not come into play one would expect the ratio between $\mathrm{Al}[3]$ and $\mathrm{Al}[4]$ ions to be more or less independent of concentration, and characteristic of the glass fabrication process. However, in a glass sample doped with $1.04 \% \quad \mathrm{Al}_{2} \mathrm{O}_{3}$ Brower did not report the $\mathrm{Al}[3] \mathrm{EPR}$ signal. ${ }^{13}$ This suggests that the $\mathrm{Al}[3]$ states at this high $\mathrm{Al}$ concentration were eliminated by the formation of $\mathrm{Al}_{4}\left[V_{O}\right]_{2}$ structures.

An EXAFS study of Al in melt-quenched silica glass was recently undertaken by Sen. ${ }^{14}$ The glass was doped with $7300 \mathrm{ppm} \mathrm{Al}_{2} \mathrm{O}_{3}$ by weight, corresponding to about 0.43 mole \%. The EXAFS results for the local environment of Al, and their comparison to the equilibrium geometries found in the present work was discussed in Sec. III A. It was found that the average bond length, bond-length dispersions, and coordination numbers in the $\mathrm{Al}_{4}\left[V_{O}\right]_{2}$ geometries were all in fair agreement with the experimental results. This is not the case for the $\mathrm{Al}_{2} V_{O}$ structure, where the bond-length dispersion due to the stretched fourth bond of the $\mathrm{Al}[4]$ ion becomes very large. Therefore Sen's results indicate that all but the most symmetric isolated $\mathrm{Al}$ ions (i.e., those having four strong bonds) have been eliminated in favor of $\mathrm{Al}_{4}\left[V_{O}\right]_{2}$ states at the $\mathrm{Al}_{2} \mathrm{O}_{3}$ concentration of 0.4 mole \%. Although this cannot be taken as a definite proof of $\mathrm{Al}_{4}\left[V_{O}\right]_{2}$ dominance, comparison with Brower's results showing a significant $\mathrm{Al}[3]$ population at an $\mathrm{Al}$ concentration two orders of magnitude lower strongly suggests that a transition from isolated $\mathrm{Al}$ to $\mathrm{Al}_{4}\left[V_{O}\right]_{2}$ structures takes place in between these two concentrations. Of course, this conclusion would be somewhat stronger if the EXAFS and EPR measurements had been performed on the same samples. 
Numerous ${ }^{27} \mathrm{Al}$ NMR studies have been made on glasses with $\mathrm{Al}_{2} \mathrm{O}_{3}$ concentrations higher than 1 mole \%. As discussed in Sec. III E, the quadrupole coupling constants contain only limited information on the local $\mathrm{Al}$ structure. The chemical shift tensor is thought to give a more reliable indication of the different $\mathrm{Al}$ coordination states. In glasses with $\mathrm{Al}_{2} \mathrm{O}_{3}$ concentrations at or below 10 mole $\%$, peaks at $\sim 0$, 30 , and $60 \mathrm{ppm}$ have been identified. ${ }^{15,53,18}$ The peaks at 0 and $60 \mathrm{ppm}$ are commonly assigned to $\mathrm{Al}[6]$ and $\mathrm{Al}[4]$, respectively. The peak around $30 \mathrm{ppm}$ is in some cases assigned to $\mathrm{Al}[5],{ }^{54}$ in others to $\mathrm{Al}[4]$ in a distorted environment. ${ }^{53}$ Somewhat mixed results regarding the concentration dependence of the peak intensities have been reported. Jin et al. studied sol-gel manufactured silica codoped with $\mathrm{Al}_{2} \mathrm{O}_{3}$ and 1 mole \% $\mathrm{Sm}_{2} \mathrm{O}_{3}$ and found mainly NMR signals from $\alpha-\mathrm{Al}_{2} \mathrm{O}_{3}$ crystallites at an $\mathrm{Al}_{2} \mathrm{O}_{3}$ concentration of 1 mole $\%{ }^{18}$ However, at 10 mole $\% \mathrm{Al}_{2} \mathrm{O}_{3}$ signals from $\mathrm{Al}[4]$ and $\mathrm{Al}[6]$ dissolved in the glass matrix were seen. Fujiyama et al., using a different sol-gel process, reported an NMR spectrum with a clear $\mathrm{Al}[4]$ peak at 3 mole $\% \mathrm{Al}_{2} \mathrm{O}_{3}$ concentration in the dried gel. ${ }^{15}$ These results indicate that the $\mathrm{Al}$ states in sol-gel glasses are strongly dependent on the fabrication method, and are not adequately described by the thermodynamic considerations used here. In a recent study by Schmücker et al. of rapidly solidified aluminosilicate melts $\left(10\right.$ mole $\left.\% \mathrm{Al}_{2} \mathrm{O}_{3}\right)$ a broad NMR signal with a peak around $30 \mathrm{ppm}$ and noticeable shoulders at 54 and $4 \mathrm{ppm}$ was reported. ${ }^{53}$ If the 30 -ppm signal is interpreted as arising from $\mathrm{Al}[5]$ this finding is strongly at variance with the results presented here, as they would then imply that the majority of the $\mathrm{Al}$ impurities would be in the $\mathrm{Al}[5]$ state. On the other hand, if the peak is caused by distorted $\mathrm{Al}[4]$ tetrahedra, the $\mathrm{Al}_{4}\left[V_{O}\right]_{2}$ structure remains a valid hypothesis. That this is the case is supported by the broad nature of the NMR signal, which suggests that a gradual variation of the chemical shift can be caused by distortion. Addition of $\mathrm{Na}_{2} \mathrm{O}$ to the melts was found to increase and sharpen the peak around $54 \mathrm{ppm}$. $\mathrm{Na}_{2} \mathrm{O}$ addition would be expected to lead to the formation of isolated $\mathrm{Al}[4]$ species compensated by $\mathrm{Na}^{+}$ions. Such $\mathrm{Al}$ impurities would have more symmetric tetrahedral environments than the $\mathrm{Al}$ ions in the $\mathrm{Al}_{4}\left[V_{O}\right]_{2}$ structures, ${ }^{55}$ and would therefore be expected to give a clearer $\mathrm{Al}[4] \mathrm{NMR}$ signal.

In summary, an analysis of theoretical and experimental results regarding $\mathrm{Al}_{2} \mathrm{O}_{3}$-doped silica glasses suggest that formation of $\mathrm{Al}_{4}\left[V_{O}\right]_{2}$ structures takes place somewhere in the concentration range between $\sim 0.01$ and 1 mole $\%$. To test this hypothesis theoretically, realistic simulations of $\mathrm{Al} \mathrm{im-}$ purity behavior in a random silica network are needed. This will involve quenches of supercells with hundreds or even thousands of atoms using realistic energy functionals such as those based on DFT, or tight-binding approximations to DFT. Presently, this appears a tall (but not completely unfeasible) order. On the experimental side, more systematic studies of $\mathrm{Al}_{2} \mathrm{O}_{3}$-doped silica in the range of low and intermediate concentrations would be needed. As is evident from the above discussion, it is important that a multitude of experimental techniques is employed simultaneously.

\section{CONCLUSIONS}

Two simple geometries for $\mathrm{Al}_{2} \mathrm{O}_{3}$ impurity units in $\mathrm{SiO}_{2}$ have been investigated by DFT calculations in an $\alpha$-quartz host. $\mathrm{Al}_{2} \mathrm{O}_{3}$ was assumed to exist either as two Sisubstitutional $\mathrm{Al}$ impurities sharing an $\mathrm{O}$ vacancy $\left(\mathrm{Al}_{2} V_{O}\right)$, or as three substitutional $\mathrm{Al}$ ions in close proximity compensated by a fourth $\mathrm{Al}$ impurity in the interstitial region of the silica network $\left(\mathrm{Al}_{4}\left[V_{O}\right]_{2}\right)$. The latter configuration was found to be energetically favored by about $1.4 \mathrm{eV}$ per $\mathrm{Al}_{2} \mathrm{O}_{3}$ unit, and simple thermodynamic estimates indicate that these states will be dominant at least for $\mathrm{Al}_{2} \mathrm{O}_{3}$ concentrations above $0.1-1$ mole $\%$. Various experimental signatures of the above-mentioned states, as well as that of a single neutral substitutional $\mathrm{Al}$ atom at an $\mathrm{O}$ vacancy $\left(\mathrm{Al} V_{O}\right)$ have been calculated. The hyperfine tensor calculated for the $\mathrm{Al}_{2} V_{O}$ state with a trapped electron in a geometry with one $\mathrm{Al}[3]$ and one $\mathrm{Al}[4]$ ion was in good agreement with a signal observed by Brower in amorphous silica. ${ }^{12,13}$ However, this geometry was destabilized by the electron addition and the hyperfine tensors for the equilibrium geometry did not correspond to experimentally observed signals, suggesting that $\mathrm{Al}[3]$ ions in amorphous silica are not paired. The ${ }^{27} \mathrm{Al}$ hyperfine tensors were found to be very small in the $\mathrm{Al} V_{O}$ states, whereas the ${ }^{29} \mathrm{Si}$ tensors were close to those found at positively charged $\mathrm{O}$ vacancies in pure silica. Core-level chemical shifts were calculated for $\mathrm{Al}$ and $\mathrm{O}$ ions in various coordination states. It was found that shifts of the $\mathrm{Al} K_{\alpha}$ flourescence line provided a measure of $\mathrm{Al}$ coordination, whereas the $1 s$ and $2 p$ level positions by themselves were more sensitive to whether the $\mathrm{Al}$ ion was substitutional or interstitial in the silica network. The O $1 s$ chemical shifts were found to be sensitive to coordination as well as the number of $\mathrm{Al}$ neighbors to the $\mathrm{O}$ ion. $\mathrm{EFG}$ parameters were evaluated for $\mathrm{Al}$ ions and their $\mathrm{O}$ neighbors, but were found to have a complicated dependence on the nature of the local environment, thus precluding the prospect of using these parameters as a measure of, e.g., the coordination state of the ions.

\footnotetext{
${ }^{1}$ S. Sen and J. Stebbins, J. Non-Cryst. Solids 188, 54 (1995).

${ }^{2}$ E. Delevaque, T. Georges, M. Monerie, P. Lomouler, and J. F. Bayon, IEEE Photonics Technol. Lett. 5, 73 (1993).

${ }^{3}$ R. H. D. Nuttall and J. A. Weil, Can. J. Phys. 59, 1696 (1981).

${ }^{4}$ R. H. D. Nuttall and J. A. Weil, Can. J. Phys. 59, 1709 (1981).

${ }^{5}$ R. H. D. Nuttall and J. A. Weil, Can. J. Phys. 59, 1886 (1981).
}

${ }^{6}$ R. S. Dickson and J. A. Weil, Can. J. Phys. 68, 630 (1990).

${ }^{7}$ D. F. Howarth, M. J. Mombourquette, and J. A. Weil, Can. J. Phys. 75, 99 (1997).

${ }^{8}$ K. Fukumi, A. Chayahara, M. Makihara, K. Fujii, J. Hayakawa, and M. Satou, J. Am. Ceram. Soc. 77, 3019 (1994).

${ }^{9}$ K. Fukumi, A. Chayahara, N. Kitamura, J. Nishii, K. Kadono, M. 
Makihara, K. Fujii, and J. Hayakawa, J. Appl. Phys. 79, 1060 (1996).

${ }^{10}$ J. Laegsgaard and K. Stokbro, Phys. Rev. B 61, 12590 (2000).

${ }^{11}$ J. Laegsgaard, Phys. Rev. B 63, 193102 (2001).

${ }^{12}$ K. L. Brower, Phys. Rev. Lett. 41, 879 (1978).

${ }^{13}$ K. L. Brower, Phys. Rev. B 20, 1799 (1979).

${ }^{14}$ S. Sen, J. Non-Cryst. Solids 261, 226 (2000).

${ }^{15}$ T. Fujiyama, T. Yokoyama, M. Hori, and M. Sasaki, J. Non-Cryst. Solids 135, 198 (1991).

${ }^{16}$ M. Schmücker, H. Schneider, and K. J. D. MacKenzie, J. NonCryst. Solids 226, 99 (1998).

${ }^{17}$ T. Schaller and J. F. Stebbins, J. Phys. Chem. B 102, 10690 (1998).

${ }^{18}$ J. Jin, S. Sakida, T. Yoko, and M. Nogami, J. Non-Cryst. Solids 262, 183 (2000).

${ }^{19}$ J. McManus, S. E. Ashbrook, K. J. D. MacKenzie, and S. Wimperis, J. Non-Cryst. Solids 282, 278 (2001).

${ }^{20}$ M. J. Mombourquette, J. A. Weil, and P. G. Mezey, Can. J. Phys. 62, 21 (1984).

${ }^{21}$ M. J. Mombourquette and J. A. Weil, Can. J. Phys. 63, 1282 (1985).

${ }^{22}$ F. Sim, C. R. A. Catlow, M. Dupuis, and J. Watts, J. Chem. Phys. 95, 4215 (1991).

${ }^{23}$ A. Continenza and A. DiPomponio, Phys. Rev. B 54, 13687 (1996).

${ }^{24}$ M. Magagnini, P. Giannozzi, and A. DalCorso, Phys. Rev. B 61, 2621 (2000).

${ }^{25}$ G. Pacchioni, F. Frigoli, D. Ricci, and J. A. Weil, Phys. Rev. B 63, 054102 (2001).

${ }^{26}$ J. Laegsgaard and K. Stokbro, Phys. Rev. Lett. 86, 2834 (2001).

${ }^{27}$ J. A. Tossell and R. E. Cohen, J. Non-Cryst. Solids 286, 187 (2001).

${ }^{28}$ M. Iglesias, K. Schwarz, P. Blaha, and D. Baldomir, Phys. Chem. Miner. 28, 67 (2001).

${ }^{29}$ E. D. Lacy, Phys. Chem. Glasses 4, 234 (1963).

${ }^{30}$ M. Boero, A. Pasquarello, J. Sarnthein, and R. Car, Phys. Rev. Lett. 78, 887 (1997).

${ }^{31}$ G. Lucovsky, A. Rozaj-Brvar, and R. F. Davis, in The Structure of Non-Crystalline Materials, edited by P. H. Gaskell, J. M. Parker, and E. A. Davis (Taylor and Francis, London, 1982), pp. 193-205.

${ }^{32}$ T. D. Taylor and G. E. Rindone, J. Am. Ceram. Soc. 53, 692 (1970).

${ }^{33}$ G. Engelhardt, M. Nofz, K. Forkel, F. G. Wihsmann, M. Mägi, A. Samoson, and E. Lippmaa, Phys. Chem. Glasses 26, 157 (1985).

${ }^{34}$ K. F. Young and H. P. R. Frederikse, J. Phys. Chem. Ref. Data 2, 313 (1973).

${ }^{35}$ P. Hohenberg and W. Kohn, Phys. Rev. 136, B864 (1964).

${ }^{36}$ W. Kohn and L. Sham, Phys. Rev. 140, A1133 (1965).

${ }^{37}$ J. P. Perdew, J. A. Chevary, S. H. Vosko, K. A. Jackson, M. R. Pederson, D. J. Singh, and C. Fiolhais, Phys. Rev. B 46, 6671 (1992).

${ }^{38}$ D. Vanderbilt, Phys. Rev. B 41, 7892 (1990).

${ }^{39}$ K. Laasonen, A. Pasquarello, R. Car, C. Lee, and D. Vanderbilt, Phys. Rev. B 47, 10142 (1993).

${ }^{40}$ J. Laegsgaard and K. Stokbro, Phys. Rev. B 63, 075108 (2001).

${ }^{41}$ P. E. Blöchl, Phys. Rev. B 50, 17953 (1994).

${ }^{42}$ G. Kresse and D. Joubert, Phys. Rev. B 59, 1758 (1999).

${ }^{43}$ C. G. VandeWalle and P. E. Blöchl, Phys. Rev. B 47, 4244 (1993).

${ }^{44}$ H. M. Petrilli, P. E. Blöchl, P. Blaha, and K. Schwarz, Phys. Rev. B 57, 14690 (1998).

${ }^{45}$ P. E. Blöchl, Phys. Rev. B 62, 6158 (2000).

${ }^{46}$ G. Pacchioni, G. Ieranò, and A. M. Marquez, Phys. Rev. Lett. 81, 377 (1998).

${ }^{47}$ P. L. Bryant, C. R. Hartwell, K. Wu, F. R. Fronczek, R. W. Hall, and L. G. Butler, J. Phys. Chem. A 103, 5246 (1999).

${ }^{48}$ M. Raymond, Phys. Rev. B 3, 3692 (1971).

${ }^{49}$ P. J. Dirken, S. C. Kohn, M. E. Smith, and E. R. H. Vaneck, Chem. Phys. Lett. 266, 568 (1997).

${ }^{50}$ Z. Xu, H. Maekawa, J. V. Oglesby, and J. F. Stebbins, J. Am. Ceram. Soc. 120, 9894 (1998).

${ }^{51}$ J. F. Stebbins, S. K. Lee, and J. V. Oglesby, Am. Mineral. 84, 983 (1999).

${ }^{52}$ S. K. Lee and J. F. Stebbins, J. Non-Cryst. Solids 270, 260 (2000).

${ }^{53}$ M. Schmücker, K. J. D. MacKenzie, H. Schneider, and R. Meinhold, J. Non-Cryst. Solids 217, 99 (1997).

${ }^{54}$ J. T. Kohli, J. E. Shelby, and J. S. Frye, Phys. Chem. Glasses 33, 73 (1991).

${ }^{55}$ M. Magagnini, Phys. Rev. B 62, 1524 (2000). 